\title{
Surface plasmon resonance in monitoring of complement activation on biomaterials.
}

$\operatorname{AUTHOR}(\mathrm{S})$ :

Arima, Yusuke; Toda, Mitsuaki; Iwata, Hiroo

\section{CITATION:}

Arima, Yusuke ...[et al]. Surface plasmon resonance in monitoring of complement activation on biomaterials.. Advanced drug delivery reviews 2011, 63(12): 988-999

\section{ISSUE DATE:}

\section{1-09-16}

URL:

http://hdl.handle.net/2433/147261

\section{RIGHT:}

(c) 2011 Elsevier B.V.; This is not the published version. Please cite only the published version.; この論文は出版社版でありません。引用の際に は出版社版をご確認ご利用ください。 
Surface plasmon resonance in monitoring of complement activation on biomaterials

Yusuke Arima, Mitsuaki Toda, and Hiroo Iwata

Institute for Frontier Medical Sciences, Kyoto University, 53 Kawahara-cho, Shogoin,

Sakyo-ku, Kyoto 606-8507, Japan

* To whom correspondence should be addressed. E-mail: iwata@frontier.kyoto-u.ac.jp,

Fax: $+81-75-751-4119$ 


\begin{abstract}
When artificial materials come into contact with blood, various biological responses are induced. For successful development of biomaterials used in biomedical devices that will be exposed to blood, understanding and control of these interactions are essential. Surface plasmon resonance (SPR) spectroscopy is one of the surface-sensitive optical methods to monitor biological interactions. SPR enables real-time and in situ analysis of interfacial events associated with biomaterials research. In this review, we describe a SPR biosensor and its application to monitor complement activation onto biomaterials surface. We also discuss the effect of surface properties of material surface on complement activation.
\end{abstract}

\title{
Keywords
}

Complement activation; surface plasmon resonance; self-assembled monolayer; polymer coating; nonspecific protein adsorption; the classical pathway; the alternative pathway 


\section{Contents}

1. Introduction

2. Surface plasmon resonance (SPR)

2.1. Principle

2.2. Real-time monitoring

2.3. Comparison to other analytical techniques

3. Model surfaces

3.1. Self-assembled monolayers of alkanethiols

3.2. Polymer thin layers

3.3. Lipid bilayer membrane

4. Complement activation on model surfaces

4.1. Monitoring of complement activation by SPR

4.2. Complement activation on model surfaces

4.2.1. Complement activation by adsorbed proteins

4.2.2. Complement activation by SAMs with various functional groups

4.2.3. Complement activation by polymer-coated surfaces

5. Conclusions and perspectives 


\section{Introduction}

When artificial materials come into contact with blood, various biological responses, such as adsorption of proteins, activation of the complement and coagulation systems, platelet activation, inflammatory reactions and cell adhesion are induced. Control of these interactions is essential for the development of biomaterials used in the preparation of biomedical devices. Thus, extensive studies have been performed to understand the interactions of blood with artificial materials.

The complement system is a cascade of enzyme reactions consisting of approximately thirty fluid-phase and cell-membrane bound proteins. It plays an important role in the body's defense systems against pathogenic xenobiotics $[1,2]$ and is also activated by artificial polymeric materials. For example, hemodialysis membranes made of cellulose or its derivatives strongly activate the complement system and this process has been extensively studied $[3,4]$. Information on the complement activation by artificial materials also has accumulated from various clinical settings, such as open heart surgery, blood transfusion medicine, and extracorporeal immunotherapies [6-8]. Understanding of complement activation on the surfaces of artificial materials is important to the rational design of biocompatible surfaces of synthetic materials. 
Complement fragments, such as C3a, iC3b, C5a, and SC5b-9, are released when artificial surfaces are exposed to serum. The interaction of complement proteins with material surfaces has been studied using enzyme-linked immunosorbent assay (ELISA) for these complement fragments study [8-14]. Recently, various analytical techniques have been examined to study biomaterials, but few of these are able to monitor dynamic interactions under physiological conditions. Surface plasmon resonance (SPR) is a surface-sensitive optical technique that allows us to follow refractive index changes near a metal surface and thus has been widely used for real-time investigations of various dynamic biological processes, such as protein-protein, DNA-DNA and proteinDNA interactions, without the need to label the sample [15-19]. For complement research, SPR has been applied to monitor individual biomolecular interactions between complement components and thus has been used to determine their rate constants and affinity constants. It has been also applied to examine formation of complement complexes such as C3 and C5 convertases. Application of SPR for these purposes has been reviewed by Ricklin and Lambris [20]. SPR also allows us to study interfacial events relating to biomaterial research since various model surfaces can be prepared on a SPR sensor chip. 
In this review, we describe application of the SPR method to study interactions of the complement system with biomaterials.

2. Surface plasmon resonance (SPR)

\subsection{Principle}

A surface plasmon is a longitudinal charge density wave that is propagated in a parallel manner along the interface of two media, where one surface is a metal and the other is a dielectric layer [21]. Metal is an essential component since the metal must exhibit free electron behavior as described by the free electron model [22]. Thus, metals like gold, silver, copper and aluminum are good candidates for optical excitation of surface plasmons, and so far most of the experimental work has been performed on gold and silver. In SPR sensors, the surface plasmon is excited by a light wave. Two different settings of optical units for the excitation of surface plasmons have been reported by Otto [23] and Kretchmann [24]. The Kretchmann configuration based on the total internal reflection (ATR) has been widely used for development of SPR instruments. In the Kretchmann configuration (Fig. 1 (a)), a beam of $p$-polarized light (light that is polarized in a plane parallel to the plane of the incident light) is used to illuminate the back side of a gold thin film (typically $\sim 50 \mathrm{~nm}$ ) on glass through a prism, and the front 
side of the film faces air or a solution of interest. When the incident angle of $p$-polarized light exceeds the critical angle, the incident light is totally reflected. A small part of the light penetrates outside the glass, and this part of the light, the so-called evanescent wave, allows us to monitor events occurring on the metal/ambient interface. The wave vector of the evanescent field $\left(k_{\mathrm{ev}}\right)$ is given by $k_{e v}=\frac{\omega}{c} \varepsilon_{g}{ }^{1 / 2} \sin \theta$

where $\omega$ is the frequency of incident light, $\mathrm{c}$ is the speed of the light, $\varepsilon_{\mathrm{g}}$ is the dielectric constant of glass ( $\varepsilon_{\mathrm{g}}^{1 / 2}$ corresponds to refractive index of glass), and $\theta$ is the incident angle. The dispersion relation for a surface plasmon propagating along the interface between a metal with a complex dielectric function $\varepsilon(\omega)=\varepsilon^{\prime}(\omega)+i \varepsilon^{\prime \prime}(\omega)$ and a dielectric with dielectric constant $\varepsilon_{\mathrm{a}}$ can be written as [22]

$$
k_{s p}=\frac{\omega}{c} \sqrt{\frac{\varepsilon^{\prime}(\omega) \varepsilon_{a}}{\varepsilon_{a}+\varepsilon^{\prime}(\omega)}}
$$

where $k_{\mathrm{sp}}$ is the wave vector for the propagating surface plasmon along the interface.

The evanescent wave of the incident light is able to couple with a surface plasmon at a specific incident angle, $\theta_{\mathrm{SPR}}$, where $k_{\mathrm{sp}}=k_{\mathrm{ev}}$, resulting in the energy loss of the incident light to the metal film and is observed as a minimum in the reflected light intensity (Fig. 1 (b)). Therefore, the SPR angle $\left(\theta_{\mathrm{SPR}}\right)$ depends on the refractive index of the medium in the vicinity of the metal film. Changes in the refractive index above the metal surface 
caused by various biological processes, such as adsorption of proteins, result in an increase of $\theta_{\mathrm{SPR}}$.

Although various SPR experimental settings have been proposed including use of a wavelength-variable light source and a diffraction grating to couple incoming light with surface plasmon $[18,19,21]$, the electromagnetic field of a surface plasmon is confined at the metal - dielectric boundary and decays exponentially with $\sim 200 \mathrm{~nm}$ of a typical penetration depth in common. SPR spectroscopy is a sensitive methodology to monitor changes in the refractive index near the metal surface and has the advantage that analytes do not need to be labeled.

\subsection{Real-time monitoring}

The optical construction of an SPR instrument is simple, as shown schematically in Fig. 1 (c). The SPR sensor is a glass plate coated with a gold $(\sim 50 \mathrm{~nm})$ with an underlayer of chromium $(\sim 1 \mathrm{~nm})$ as an adhesive layer. The plate is optically coupled to a glass prism using an index-matching fluid. A $p$-polarized laser beam is directed to the back side of a sample plate through a glass prism and reflected light intensity is monitored. By changing the incident angle of the laser beam, we can determine the SPR angle $\left(\theta_{\mathrm{SPR}}\right)$ as the minimum in reflectance (Fig. 1 (b)). If substances are deposited onto the 
sensor surface, a shift in $\theta_{\mathrm{SPR}}$ occurs $\left(\Delta \theta_{\mathrm{SPR}}\right)$ in a manner dependent on the amount of the deposited substances.

For real-time monitoring, the reflected light intensity is detected with respect to time (Fig. 2). Initially, a buffer solution is infused into a flow cell which is set up on the sensor surface to obtain a baseline (Fig. 2, process I). When a protein solution is subsequently circulated, a large increase in reflectance is observed due to the change in the refractive index of the solution (bulk effect) and the adsorption of proteins (Fig. 2, II). After circulation of the protein solution for a predetermined period (Fig. 2, III), a buffer solution is infused to wash the protein solution out and to remove loosely bound proteins (Fig. 2, IV). An increase in reflectance $(\Delta R)$ can be converted to the SPR angle shift $\left(\Delta \theta_{\mathrm{SPR}}\right)$ and the amount of adsorbed proteins is calculated from $\Delta \theta_{\mathrm{SPR}}$. The thickness of the protein layer, the amount of protein adsorbed, was calculated from the shift in the SPR angle $\left(\Delta \theta_{\mathrm{SPR}}\right)$ using Fresnel fits for the system glass/Cr/Au/SAM/protein/water [25,26].

2.3. Comparison to other analytical techniques 
Various analytical methods have been developed to study interactions between biomolecules $[27,28]$. Some of them have been applied to monitor complement activation on biomaterials (Table 1).

Ellipsometry has been used to probe proteins at interfaces, and has been applied to blood coagulation [29-32] and complement activation [33-40]. Ellipsometry allows for determination of the amount of protein adsorbed on reflecting materials such as silicon wafers and gold-coated silicon. The amount of adsorbed proteins can be determined in air and also in solution. Therefore, ellipsometry and SPR give similar information on proteins adsorbed onto the material surface, although the setting of optical units of SPR is simple compared to that of ellipsometry.

The quartz crystal microbalance (QCM) has also been used to study complement activation on material surface [41-43]. An increase in mass bound to the quartz surface causes the crystal's oscillation frequency to decrease, allowing for label-free and realtime monitoring. A recently developed QCM with dissipation monitoring (QCM-D) allows simultaneous and simple measurements of changes in adsorbed mass as well as in the viscoelastic property of the deposited protein layers on the sensor surface [44]. Simultaneous analysis by QCM-D and SPR has been reported to provide several types 
of information about the adsorbed substances, such as the adsorbed mass and the coupled water mass [45].

Complement activation by biomaterials has been studied using enzyme-linked immunosorbent assay (ELISA) [8-14]. In these experiments, complement fragments, such as $\mathrm{C} 3 \mathrm{a}$, iC3b, C5a, and SC5b-9, released into serum were determined after exposure of sample surfaces to human serum. In contrast, SPR detects dynamic processes of protein deposition on the surface. Subsequent binding of antibodies allows for identification of the deposited proteins without the need for additional labeling. Therefore, ELISA and SPR measurements provide complementary approaches to examine complement activation on material surface.

\section{Model surfaces}

A metal-coated glass plate is used as a sensor chip in SPR measurement. A thin model layer should be formed on the metal surface. Serum is then exposed to the model surface to examine complement activation on organic materials. Many methodologies have been reported to prepare a model organic layer on a metal surface (Fig. 3).

3.1. Self-assembled monolayers of alkanethiols 
Self-assembled monolayers (SAMs) of alkanethiols, $\mathrm{HS}\left(\mathrm{CH}_{2}\right)_{\mathrm{n}} \mathrm{X}$ in which $\mathrm{X}$ denotes various functional groups, are frequently used to prepare model surfaces [46-49]. Alkanethiols or alkanedisulfides chemisorb from a solution onto a metal surface such as gold, silver, and platinum. A gold thin layer on a glass plate is commonly used to form SAMs because it is easy to prepare and is stable in the ambient environment. The gold sulfur bond is relatively stable with $\Delta \mathrm{H}^{\mathrm{o}} \approx 28 \mathrm{kcal} / \mathrm{mol}[50,51]$. In addition, van der Waals interaction between each alkyl chain leads to self-assembly of the alkanethiol. Alkanethiols carrying long alkyl chain $(\mathrm{n}>11)$ form closely packed SAMs with approximately $21.4 \AA^{2}$ of occupied area per molecule [52,53]. Due to anchoring of the thiol to gold and the close packing of the alkyl chain, another terminal group, $\mathrm{X}$, is effectively displayed at the surface of the SAM. Alkanethiols with various functional groups, $\mathrm{X}$, are commercially available. It is easy to prepare SAMs with different functional groups.

In addition, surface properties of SAMs can be finely controlled by coadsorption of alkanethiols from their mixed solutions. The composition of alkanethiols in SAMs reflects the mole fraction of alkanethiols in solution, but is not the same as their composition in the solution. The composition of SAMs can be determined by spectroscopic methods such as Fourier transformed infrared - reflection adsorption 
spectroscopy (FTIR-RAS) and X-ray photoelectron spectroscopy (XPS). Figure 4 summarizes mixed SAMs which are prepared from a mixture of hydroxyl-terminated alkanethiol (11-mercapto-1-undecanol) and methyl-terminated alkanethiols with different alkyl chain length [54]. The surface composition of the alkanethiol in the mixed SAM was determined from the FTIR-RAS spectra using an absorption band assigned to the asymmetric stretching mode of the methyl groups. The surface fraction of the alkanethiols in the mixed SAM does not linearly reflect the mole fraction in the original solution (Fig. 4 (a)). Rather, it is highly dependent on the chain length of alkanethiols and the terminal functional groups $[55,56]$. The water contact angle measurement indicates that mixed SAMs become more hydrophilic as the surface fraction of the hydroxyl-terminated alkanethiol increases (Fig. 4 (b)). Thus, the preparation of mixed SAMs from a mixture of different alkanethiols allows us to systematically change surface properties, and provides different kinds of model surfaces for studies of complement activation on artificial materials.

\subsection{Polymer thin layers}

Polymers have also been used to prepare model surfaces on SPR sensors. Water-soluble polymers, such as dextran [57] and poly(ethylene glycol) (PEG) [58], carrying thiol 
groups on side chains or at a chain end directly chemisorb onto the gold surfaces through gold - sulfur bond. Surface modification of the sensor surface with watersoluble polymers has also been performed by covalently immobilization [59-61] or physical adsorption [62] on SAMs. For water-insoluble polymers such as polystyrene, thin films with various thicknesses can be easily prepared by the spin-coating onto sensor surfaces.

It should be noted that SPR is used to monitor local changes in refractive index in the vicinity on the sensor surfaces. The decay length of the surface plasmon field is typically $200 \mathrm{~nm}$ from the metal surface [63]. If polymer layers on the sensor surface are thicker than the decay length, adsorption of proteins onto the polymer layer can hardly be determined by SPR. Therefore, the thickness of the polymer layers should be controlled to effectively monitor the interfacial events on the polymer layers. The thickness of the dry polymer layer is determined using SPR by fitting a parameter of Fresnel's law for a multi-layer system to measured data with, for example, glass $/ \mathrm{Cr} / \mathrm{Au} /$ polymer/air $[25,26]$. Using the refractive indices of each layer, the thickness of the polymer layer can be obtained. For a substrate carrying a water-soluble polymer, swelling of the polymer layer must be taken into consideration. We 
successfully estimated the thickness of swelled polymer layers including poly $(N-$ isopropylacrylamide) (PNIPAAm) [64] and PVA [61] using SPR.

\subsection{Lipid bilayer membrane}

Activation of the complement system by the cell membranes of pathogenic xenobiotics is critical in the body's defense. Since liposomes are used in pharmaceutical applications, it is also important to understand complement activation by liposomal membranes. Lipid membranes have been fabricated on solid substrates and these have been applied to the study of protein-lipid membrane interactions. Various methods have been reported to prepare lipid membranes onto an SPR sensor chip, including solidsupported lipid bilayers, polymer-cushioned lipid bilayers, hybrid bilayers, and tethered lipid bilayers [65]. In each of these examples, lipid molecules in the membrane maintain its lateral mobility. In addition, incorporation of membrane proteins into the lipid membranes has been developed [66].

4. Complement activation on model surfaces

4.1. Monitoring of complement activation by SPR 
A typical SPR sensorgram obtained during exposure of human serum to an SPR sensor carrying a SAM composed of hydroxyl-terminated alkanethiols is shown in Figure 5 [67]. The sensor surface was sequentially exposed to veronal buffer (VB), human serum, VB, and finally, a solution of anti-C3b antibody. The sudden increase of the SPR angle observed by exposure to human serum is due to the increase in the refractive index near the sensor surface (bulk effect) and non-specific adsorption of serum proteins. The SPR angle then gradually increased (see Fig. 5, inset in more detail) and leveled off, reflecting additional deposition of serum proteins on the surface. It is considered to be due to the complement activation on the surface. When $\mathrm{C} 3 \mathrm{~b}$ is deposited on the material surface, it forms $\mathrm{C} 3$ convertase $\mathrm{C} 3 \mathrm{bBb}$, which cleaves $\mathrm{C} 3$ in the vicinity of the surface into $\mathrm{C} 3 \mathrm{a}$ and $\mathrm{C} 3 \mathrm{~b}$. The rate of $\mathrm{C} 3 \mathrm{~b}$ deposition onto the surface is accelerated by an autocatalytic positive feedback mechanism after $\mathrm{C} 3$ convertase has been generated once. When the serum was removed by infusing VB into the flow cell, a slight decrease in the SPR angle occurred reflecting the change in the refractive index of the solution and the removal of loosely adsorbed proteins. The SPR angle shift ( $\triangle \mathrm{SPR}$ in Figure 5$)$ after rinsing with $\mathrm{VB}$ is attributed to serum protein adsorption and the amount of proteins on the surface can be calculated from the $\Delta$ SPR (see section 2.2). When the complement system is activated on the sensor surface, $\mathrm{C} 3$ fragments such as $\mathrm{C} 3 \mathrm{~b}$ and $\mathrm{C} 3 \mathrm{c}$ are 
expected to be immobilized on the protein layer formed on the sensor surface. When a solution of antibody against C3 fragments was applied, the SPR angle should increase further. Figure 5 illustrates that the SPR angle actually increased during application of anti-C3b antiserum, indicating that large amount of $\mathrm{C} 3 \mathrm{~b}$ or $\mathrm{C} 3 \mathrm{bBb}$ was deposited on the surface. Thus, SPR allows us to monitor the complement activation on the sensor surface.

The above claim was supported by ELISA of the fragments of complement proteins produced during the complement activation. Human serum was incubated with surfaces and then concentrations of complement fragments or complex $(\mathrm{C} 3 \mathrm{a}, \mathrm{Bb}, \mathrm{C} 5 \mathrm{a}$, or $\mathrm{SC} 5 \mathrm{~b}-$ 9) in it were determined by ELISA. Surfaces on which a large amount of anti-C3b antibody was deposited also produced fragments of complement proteins, such as $\mathrm{Bb}$, C3a, C5a, and SC5b-9 in serum [60,61,67-70]. Combination of SPR and ELISA provides complementary information of complement activation behavior on material surfaces, while SPR is superior in rapid and real-time monitoring of complement activation compared to ELISA.

The complement system has three activation pathways, the classical, alternative and lectin pathways. Activation of a specific pathway is highly dependent on the materials. The addition of specific reagents to serum can determine which pathway is activated. 
Ethylenediaminetetraacetic acid (EDTA) inhibits all three pathways. Ethylene glycolbis[ $\beta$-aminoethyl ether]- $N, N, N$ ', $N$ '-tetraacetic acid (EGTA) and $\mathrm{MgCl}_{2}$ block only the classical pathway. The alternative pathway can be blocked by compstatin or its cyclic analog [71-73]. Use of serum depleted of complement protein or addition of antibodies against complement-relating proteins, auch as $\mathrm{IgG}, \mathrm{C} 1 \mathrm{q}, \mathrm{C} 4$, also gives us additional information about the complement activation cascade including initiation, formation of $\mathrm{C} 3$ and C5 convertase.

Monitoring of complement cascade on the surface by binding of specific antibodies should be carefully interpreted. Complement activation results in deposition of a large amount of complement proteins on the surface. Underlying proteins such as $\operatorname{IgG}, \mathrm{Clq}$, C4 are only transiently detected by specific antibodies due to steric hindrance by serum proteins deposited at late stage. This has been encountered regardless of apparatus employed, SPR or ellipsometry, when surface-bound antigens are detected using specific antibodies $[34,36,37,42,74]$. Therefore, comprehensive approaches including choice of serum incubation time, inhibitors, and detection of complement fragments by ELISA are required to conclude which complement cascade is activated on the surface. 
Several mechanisms have been proposed to explain complement activation by artificial materials (Fig. 6). Its activation is triggered by (a) nonspecifically adsorbed immunoglobulins; (b) conformational change of adsorbed C3 into a C3b-like structure; (c) covalent binding of $\mathrm{C} 3 \mathrm{~b}$ to adsorbed serum proteins; and (d) covalent binding of $\mathrm{C} 3 \mathrm{~b}$ to artificial materials.

\subsubsection{Complement activation by adsorbed proteins}

The classical pathway is initiated by antigen-antibody complexes formed onto pathogens. Few specific antibodies against artificial materials, such as antibodies against PEG [75], can activate the complement through the classical pathway.

Nonspecific adsorption of immunoglobulins is thought to induce the complement activation through the classical pathway (Fig. 6 (a)). Preadsorption of IgG, IgA, or IgM to surfaces has been shown to induce strong complement activation $[36,37,39,40,74]$.

Although preadsorbed immunoglobulins initiate the complement activation through the classical pathway, they can also be substrates for covalent binding of $\mathrm{C} 3 \mathrm{~b}$ which is generated in the liquid phase or during complement activation [42]. The immunoglobulin-C3b complex can activate the complement activation through the alternative pathway (Fig. 6 (c)). Preadsorbed albumin was also shown to be a substrate 
for covalent binding of $\mathrm{C} 3 \mathrm{~b}$ [42]. Adsorption of $\mathrm{C} 3$ induces conformational changes that transform $\mathrm{C} 3$ into a $\mathrm{C} 3 \mathrm{~b}$-like molecule that is able to participate in the functioning of the alternative convertase [41] (Fig. 6 (b)).

These results suggest that adsorbed serum proteins have the potential ability to trigger both the classical and the alternative pathways depending on the type of the adsorbed protein.

\subsubsection{Complement activation by SAMs with various functional groups}

The effect of surface functional groups on complement activation has been studied by taking advantage of SAMs composed of alkanethiols. Figure 7 compares the amounts of protein adsorbed on SAMs carrying hydroxyl $(\mathrm{OH})$, amino $\left(\mathrm{NH}_{2}\right)$, methyl $\left(\mathrm{CH}_{3}\right)$ and carboxyl $(\mathrm{COOH})$ terminal groups from human serum $[68,70]$. SAMs modified with hydroxyl groups (OH-SAM) showed the highest amount of adsorbed serum proteins (Fig. 7). Four solutions of different antibodies were applied to the adsorbed protein layers to analyze the activation pathway. A large amount of anti-C3b antibody was bound to the adsorbed protein layer, formed on OH-SAM, indicating that strong complement activation occurs on $\mathrm{OH}-\mathrm{SAM}$ through the alternative pathway. This result is consistent with earlier studies that demonstrated that hemodialysis membranes made 
of cellulose or its derivatives activated the complement system $[3,4]$. Notably, anti-C1q, anti-albumin or anti-IgG were hardly detected in the protein layer formed on OH-SAM. Most of the adsorbed protein in the layer is composed of $\mathrm{C} 3 \mathrm{~b}$ and $\mathrm{C} 3 \mathrm{bBb}$. In contrast, SAMs carrying methyl $\left(\mathrm{CH}_{3}\right)$, amine $\left(\mathrm{NH}_{2}\right)$, and carboxylic acid $(\mathrm{COOH})$ terminal groups exhibited less binding of anti-C3b antibody, indicating that those functional groups are poor complement activators through either the classical or the alternative pathways. These results clearly demonstrate that surface functional groups greatly affect the complement activation behavior.

The amino group, which is similar to the hydroxyl group in that both are nucleophiles, seems to be a potential activator for the complement system. Indeed, low molecular weight amines in blood react with the thioester group of C3 [76-78] and C3b [78]. However, SAMs carrying terminal amino group $\left(\mathrm{NH}_{2}-\mathrm{SAM}\right)$ did not exhibit high levels of C3b deposition [68] (Fig. 7). ELISA study also showed that the amount of C3a released into serum after exposure to $\mathrm{NH}_{2}$-SAM was much less than with $\mathrm{OH}-\mathrm{SAM}$. About $750 \mu \mathrm{g} / \mathrm{cm}^{2}$ of protein, mainly albumin, was adsorbed onto the $\mathrm{NH}_{2}-\mathrm{SAM} . \mathrm{NH}_{2}$ SAM was a much weaker activator due to coverage of nucleophilic amino groups with serum proteins. 
To examine the effect of hydroxyl density on complement activation, mixed SAMs with different ratios of hydroxyl and methyl groups were prepared using 11-mercapto-1undecanethiol and methyl-terminated alkanethiol with different alkyl chain length (1nonanethiol, 1-dodecanethiol, or 1-hexadecanethiol). Figure 8 shows deposition of protein from human serum on the mixed SAMs [54]. The amounts of adsorbed serum proteins increased with increasing surface fraction of hydroxyl groups C11-OH (Fig. 8). We also examined adsorption of human serum albumin (HSA) to mixed SAMs. HSA did not adsorb to SAMs with high hydroxyl fraction. The amount of bound anti-C3b antibody also increased with increasing surface fraction of hydroxyl group [54]. A small amount of $\mathrm{C} 3 \mathrm{~b}$ is naturally produced in the liquid phase, serum, by hydrolysis. It is covalently immobilized on the surface through the ester exchange reaction between the thioester of $\mathrm{C} 3 \mathrm{~b}$ and surface hydroxyl groups. The $\mathrm{C} 3 \mathrm{~b}$ is stabilized on the surface and then becomes the $\mathrm{C} 3$ convertase, $\mathrm{C} 3 \mathrm{bBb}$. It accelerates activation of the complement system. The surface with higher density of hydroxyl groups becomes a potent activator of the complement through the alternative pathway.

Although OH-SAM exhibited low adsorption of albumin, the surface did not fully inhibit nonspecific protein adsorption even in the presence of EDTA [67]. Tengvall et al. reported complement activation on a surface modified with 3-mercapto-1,2-propanediol 
using ellipsometry [33]. They showed that $\mathrm{IgG}$ and C1q was transiently detected on the surface exposed to human serum by their specific antibodies. They speculated that $\operatorname{IgG}$ adsorbed on the surfaces initially activates the complement through the classical pathway and then deposited $\mathrm{C} 3 \mathrm{~b}$ accelerated its activation through the alternative pathway. Further studies including composition of initially adsorbed proteins and their conformation on the surface are required to discuss the detailed mechanism of the complement activation by surfaces carrying hydroxyl groups.

\subsubsection{Complement activation by polymer-coated surfaces}

Coating of biomaterials and biosensors with water soluble polymers including poly(ethylene glycol) (PEG), dextran, and poly(vinyl alcohol) (PVA) has been shown to effectively prevent nonspecific adsorption of proteins. PEG has been frequently used to shield the antigenicity of proteinaceous drugs from the host immune system, and to prolong the circulating half-life of drug-loaded nanoparticles [79-81]. However, unanticipated body reactions such as hypersensitivity reactions caused by PEGmodified liposomes [82-85] and rapid clearance of PEG-modified liposomes from blood have been reported [86]. The complement system is suggested to be associated with these body reactions [87-89], but the detailed mechanism remains unclear. To aid the 
development of PEG-modified materials for biomedical and pharmaceutical use, the interactions of complement proteins with PEG-modified surfaces have been studied in some detail.

Two surfaces modified with tri(ethylene glycol)-terminated alkanethiol (HS-TEGOH) and methoxy-terminated PEG-thiol (HS-mPEG) were employed as model surfaces in our studies [90]. While these surfaces demonstrated nonspecific protein adsorption from solutions of a single protein such as albumin, IgG, and fibrinogen [58,91,92], large amounts of serum proteins were deposited on the HS-TEGOH surface when the surface was exposed to human serum (Fig. 9 (a)). A large amount of anti-C3b antiserum also bound to the protein layer formed on the HS-TEGOH surface (Fig. 9 (b)), indicating that the complement system is strongly activated by the HS-TEGOH surface. In addition, when human serum was supplemented with EDTA, which can inhibit the complement activation, deposition of serum proteins was greatly reduced. HS-TEGOH affords a non-fouling surface in the presence of EDTA as observed in single protein solutions. In addition, when human serum was supplemented with EGTA and $\mathrm{Mg}^{2+}$, a large amount of anti-C3b antibody was immobilized on the protein layer formed on the HS-TEGOH surface. Those results indicate that $\mathrm{C} 3 \mathrm{~b}$ covalently binds to the terminal hydroxyl group of HS-TEGOH (Fig. 6 (d)) and the HS-TEGOH surface activates the 
complement system through the alternative pathway. In contrast, small amounts of serum proteins were deposited on the HS-mPEG surface which carries a methoxy terminal group, and no anti-C3b antibody was immobilized on the surface previously exposed to human serum. These results suggest that soluble PEG chains can inhibit nonspecific protein adsorption and the terminal group of PEG can determine the complement activation behavior. These results are consistent with previous studies in which nanoparticles modified with methoxy-terminated PEG reduce complement activation, cellular uptake and prolong circulation lifetime in blood, while the stealth properties of PEG-modified nanoparticles depend on their size, and surface density of PEG $[87,89,93]$.

Although the HS-mPEG surface just after preparation did not induce complement activation, it became a stronger activator upon storage under room light at room temperature $[69,90]$. Conversion of the HS-mPEG surface into a complement-activating surface highly depended on the storage conditions (temperature, light). Complement activation on the HS-mPEG surface was further accelerated by UV irradiation. Surface analyses using FTIR-RAS and XPS confirmed that the HS-mPEG surface was degraded during storage or UV irradiation [69]. Sufficient PEG chains remained to prevent 
protein adsorption on the HS-mPEG surface, if the complement activation was inhibited by EDTA.

The PEG chains appear to be degraded by the following mechanism [94]:

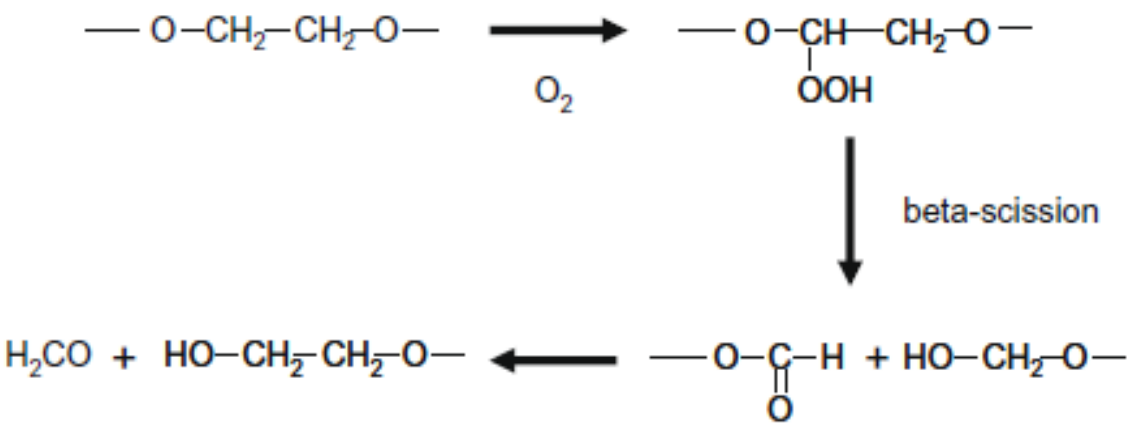

The resulting fragments of PEG chains carry hydroxyl groups at the terminal and thus have the ability to activate the complement activation as observed with the HS-TEGOH surface. Oxidation should be suppressed for future development of PEG-coated materials for use in biomedical applications.

PVA and dextran are also useful to prevent nonspecific protein adsorption as observed with PEG. However, these polymers are expected to have the potential ability to activate the complement system due to the presence of many hydroxyl groups on the molecule as cellulose. Indeed, surfaces modified with PVA and dextran strongly activated the complement system [60]. These surfaces effectively prevented nonspecific adsorption of serum proteins. Deposition of $\mathrm{C} 3 \mathrm{~b}$ was not reduced even in the presence of EGTA-Mg ${ }^{2+}$, suggesting that the complement activation is mainly initiated through the alternative pathway. Interestingly, these polymers added to serum did not activate the complement 
system even when the amounts of the soluble polymers added to serum were $4-2000$ times higher than those on the polymer-immobilized surfaces. Videm et al. also reported that solutions of dextran, which have medicinal application as a blood substitute and a plasma expander, did not strongly activate the complement system at the dextran concentrations used in clinical settings [95]. These results suggest that conformation of polymer in solution and immobilized on solid surface determine the complement activation behavior.

The potential of PVA immobilized surfaces as an activator of the complement system was examined in some detail [61]. PVA was immobilized on SAM of alkanethiol carrying a terminal aldehyde group by spin-coating PVA in the presence of $\mathrm{HCl}$. The thickness of the PVA layers was controlled by the concentrations of PVA used for spincoating (Table 2). Complement activation by PVA surfaces highly depends on its thickness and annealing temperature [60] (Fig. 10). The complement system was strongly activated by a PVA immobilized surface with a dry thickness of $2.9 \mathrm{~nm}$ as indicated by large amounts of adsorbed serum proteins and subsequently bound antiC3b antibody, while it was poorly activated by a PVA surface with a dry thickness of 7.4 $\mathrm{nm}$. In addition, annealing of the latter for $2 \mathrm{~h}$ at $150{ }^{\circ} \mathrm{C}$ converted the surface into a complement activating surface. Non-specific protein adsorption was prevented on all 
surfaces when serum supplemented with EDTA was used. On the other hand, large amounts of adsorbed proteins and bound anti-C3b antibodies were observed on PVA surfaces in serum supplemented with EGTA and $\mathrm{Mg}^{2+}$. These results suggest that the PVA surfaces activate the complement system through the alternative pathway. The difference in the complement activation ability of PVA layers was intimately related with the water content of the PVA layers (Table 2). A surface with a thick PVA layer, which poorly activates the complement system, showed high water content $(86 \%)$, while surfaces with thin PVA layer and annealed thick PVA layer, which are strong complement activators, exhibited low water content $(37-75 \%)$. We speculate that the difference between these PVA layers can be explained by accessibility of complement regulatory factors $\mathrm{H}$ and $\mathrm{I}$ to their respective binding sites between polymers and $\mathrm{C} 3 \mathrm{~b}$. For the case of surfaces with poorly hydrated PVA layers, activator (factor B) is expected to interact with specific binding sites of $\mathrm{C} 3 \mathrm{~b}$ on poorly hydrated PVA layers, while factors $\mathrm{H}(155 \mathrm{kDa})$ and $\mathrm{I}(88 \mathrm{kDa})$ hardly have access to their binding sites on $\mathrm{C} 3 \mathrm{~b}$ since the binding sites are hindered by PVA chains and a planar substrate. On the other hand, for the case of surfaces with highly hydrated PVA layers, the regulators (factors $\mathrm{H}$ and I) accesses to their binding sites of $\mathrm{C} 3 \mathrm{~b}$ bound to highly hydrated PVA. 
These speculations can be also applicable to poor activation ability of polymers with hydroxyl groups (PVA and dextran) dissolved in serum.

Effect of polymer conformations on complement activation was also reported $[87,89,96-$ 99]. Hamad et al used polystyrene nanoparticles coated by poloxamine 908 , a tetrafunctional polyethylene oxide - polypropylene oxide ethylenediamine block copolymer carrying terminal hydroxyl group [99]. They showed that polymer architecture from mushroom to brush configuration not only reduces the level of the complement activation but also switches complement activation pathway. These reports suggest that conformation of polymer should be controlled to design biomaterials including blood vessel prostheses, drug-loaded nanoparticles, and polymer-modified drug. Molecular basis of complement activation on polymer surfaces with different conformations is needed to be studied on the base of three dimensional molecular structures of complement proteins.

\section{Conclusions and perspectives}

Synthetic materials have been widely used for biomedical and pharmaceutical applications, such as blood vessel prostheses, hemodialysis membranes, and drug eluting systems and liposomes. For the successful development of biomaterials that will 
come in contact with blood, understanding and control of complement activation on biomaterials are essentially important. SPR is one of the analytical techniques that allows for in situ monitoring of complement activation on the surfaces of materials.

Studies on complement activation on various material surfaces have revealed that:

1. Protein adsorption behavior from human serum differs from that in a single protein solution.

2. Surfaces carrying hydroxyl groups strongly activate the complement system through the alternative pathway.

3. Surfaces carrying amino groups are poor activators of the complement system.

4. Polymer layers presenting hydroxyl groups strongly activate the complement system through the alternative pathway. However, this behavior highly depends on the water content of the polymer layer.

Although studies cited in this review and others made clear the mechanisms of the complement activation by the artificial materials, several points still remain to be clarified.

1. What is the critical step for complement activation on a nonspecifically adsorbed protein layer? 
2. How does the water content of the polymer layer modulate the complement activation behavior?

3. Do lipid bilayers or polymer-modified lipid bilayers activate the complement system?

Recently, three dimensional structures of complement-relating proteins and their complexes have been revealed by X-ray diffraction and electron microscopy [100-107]. The structural studies provided deep insights into complement activation/regulation on the molecular level. Although advances in molecular biology have also provided detailed and comprehensive information about networks of complement activation/regulation, a complete understanding of its network reactions has yet to be accomplished. Recently, developments in systems biology have aided our understanding of dynamic biological networks using a mathematical model [108]. We have attempted to apply the methodology of systems biology to extend our understanding of the complement activation cascade induced by biomaterials. The combination of these studies with analytical techniques will ultimately allow us to understand the mechanisms of complement activation on biomaterials's surfaces.

\section{Acknowledgements}


This study was partly supported by a Grant-in-Aid for Scientific Research (A) (No.

21240051) from the Ministry of Education, Culture, Sports, Science, and Technology

(MEXT) of Japan, by a project of Kyoto City Collaboration of Regional Entities for the

Advancement of Technological Excellence, and by Development of Systems and

Technology for Advanced Measurement and Analysis, JST, Japan. 


\section{References}

1. M.J. Walport, Complement, N. Engl. J. Med. 344 (2001) 1058-1066.

2. D. Ricklin, G. Hajishengallis, K. Yang, J.D. Lambris, Complement: a key system for immune surveillance and homeostasis, Nat. Immunol. 11 (2010) 785-797.

3. D.E. Chenoweth, Complement activation during hemodialysis: Clinical observations, proposed mechanisms, and theoretical implications, Artif. Organs 8 (1984) 281-290.

4. E. Wegmuller, A. Montandon, U. Nydegger, C. Descoeudres, Biocompatibility of different hemodialysis membranes: Activation of complement and leukopenia, Int. J. Artif. Organs 9 (1986) 85-92.

5. D.E. Chenoweth, S.W. Cooper, T.E. Hugli, R.W. Stewart, E.H. Blackstone, J.W. Kinklin, Complement activation during cardiopulmonary bypass: Evidence for generation of C3a and C5a anaphylatoxins, N. Engl. J. Med. 344 (2001) 1058-1066.

6. Y.J. Gu, W. van Oeveren, Activation of plasma components by leukocyte removal filters, ASAIO J. 40 (1994) 598-601.

7. F. Maillet, M. Petitou, J. Choay, D. Kazatchkine, Structure-function relationship in the inhibitory effect of heparin on complement activation: Independency of the anticoagulant and anti-complementary sites on the heparin molecule, Mol. Immunol. 25 
(1988) 917-923.

8. E.L. Chaikof, E.W. Merrill, A.D. Callow, R.J. Connolly, S.L. Verdon, K. Ramberg, PEO enhancement of platelet deposition, fibrinogen deposition, and complement C3 activation, J. Biomed. Mater. Res. 26 (1992) 1163-1168.

9. M. Berger, B. Broxup, M.V. Sefton, Using Elisa to evaluate complement activation by reference biomaterials, J. Mater. Sci. Mater. Med. 5 (1994) 622-627.

10. A. Kidane, K. Park, Complement activation by PEO-grafted glass surfaces, J. Biomed. Mater. Res. 48 (1999) 640-647.

11. M.B. Gorbet, M.V. Sefton, Complement inhibition reduces material-induced leukocyte activation with PEG modified polystyrene beads (Tentagel ${ }^{\mathrm{TM}}$ ) but not polystyrene beads, J. Biomed. Mater. Res. 74A (2005) 511-522.

12. H.S. Jang, K.E. Ryu, W.S. Ahn, H.J. Chun, H.D. Park, Y.H. Kim, Complement activation by sulfonated poly(ethylene glycol)-acrylate copolymers through alternative pathway, Colloids Surf. B 50 (2006) 141-146.

13. J. Szebeni, L. Baranyi, S. Savay, H.U. Lutz, E. Jelezarova, R. Bunger, C.R. Alving, The role of complement activation in hypersensitivity to pegylated liposomal doxorubicin $\left(\right.$ Doxil $\left.^{\circledR}\right)$, J. Liposome Res. 10 (2000) 467-481.

14. J. Szebeni, L. Baranyi, S. Savay, J. Milosevits, R. Bunger, P. Laverman, J.M. 
Metselaar, G. Storm, A. Chanan-Khan, L. Liebes, F.M. Muggia, R. Cohen, Y.

Barenholz, C.R. Alving, Role of complement activation in hypersensitivity reactions

to Doxil and hynic PEG liposomes: Experimental and clinical studies, J. Liposome Res. 12 (2002) 165-172.

15. I. Lundström, Real-time biospecific interaction analysis, Biosens. Bioelectron. 9 (1994) 725-736.

16. J. Homola, S.S. Yee, G. Gauglitz, Surface plasmon resonance sensors: review, Sens. Actuators B 54 (1999) 3-15.

17. R.J. Green, R.A. Frazier, K.M. Shakesheff, M.C. Davies, C.J. Roberts, S.J.B. Tendler, Surface plasmon resonance analysis of dynamic biological interactions with biomaterials, Biomaterials 21 (2000) 1823-1835.

18. J. Homola, Present and future of surface plasmon resonance biosensors, Anal. Bioanal. Chem. 377 (2003) 528-539.

19. J. Homola, Surface plasmon resonance sensors for detection of chemical and biological species, Chem. Rev. 108 (2008) 462-493.

20. D. Ricklin, J.D. Lambris, Exploring the complement interaction network using surface plasmon resonance, Adv. Exp. Med. Biol. 598 (2007) 260-278.

21. H. Raether, Surface plasmons on smooth and rough surfaces and on gratings, 
Springer, Berlin, 1988.

22. A.D. Boardman, Electromagnetic surface modes, Wiley, Chichester, 1982.

23. A. Otto, Excitation of nonradiative surface plasma waves in silver by the method of frustrated total reflection, Z. Phys. 216 (1968) 398-410.

24. E. Kretchmann, The determination of the optical constants of metals by excitation of surface plasmons, Z. Phys. 241 (1971) 313-324.

25. R.M.A. Azzam, N.M. Bashara, Ellipsometry and polarized light, North-Holland Publishing Company, Amsterdam, 1977.

26. W. Knoll, Polymer thin films and interfaces characterized with evanescent light, Makromol. Chem. 192 (1991) 2827-2856.

27. G. Gauglitz, Direct optical sensors: principles and selected applications, Anal. Bioanal. Chem. 381 (2005) 141-155.

28. G. Gauglitz, Direct optical detection in bioanalysis: an update, Anal. Bioanal. Chem. 398 (2010) 2363-2372.

29. L. Vroman, A.L. Adams, Identification of rapid changes at plasma-solid interfaces, J. Biomed. Mater. Res. 3 (1969) 43-67.

30. H. Elwing, A. Askendal, I. Lundström, Competition between adsorbed fibrinogen and high-molecular-weight kininogen on solid surfaces incubated in human plasma 
(the Vroman effect): Influence of solid surface wettability, J. Biomed. Mater. Res. 21 (1987) 1023-1028.

31. B. Wälivaara, A. Askendal, I. Lundström, P. Tengvall, Blood protein interactions with titanium surfaces, J. Biomater. Sci. Polymer Ed. 8 (1996) 41-48.

32. M. Lestelius, B. Liedberg, P. Tengvall, In vitro plasma protein adsorption on $\omega$ functionalized alkanethiolate self-assembled monolayers, Langmuir 13 (1997) 5900-5908.

33. H. Elwing, B. Ivarsson, I. Lundström, Complement deposition from human sera on silicon surfaces studied in situ ellipsometry: The influence of surface wettability, Eur. J. Biochem. 156 (1986) 359-365.

34. P. Tengvall, A. Askendal, I. Lundström, Complement activation by 3-mercapto-1,2propanediol immobilized on gold surfaces, Biomaterials, 17 (1996) 1001-1007.

35. L. Liu, H. Elwing, Complement activation on thiol-modified gold surfaces, J. Biomed. Mater. Res. 30 (1996) 535-541.

36. P. Tengvall, A. Askendal, I. Lundström, Complement activation by IgG immobilized on methylated silicon, J. Biomed. Mater. Res. 31 (1996) 305-312.

37. P. Tengvall, A. Askendal, I. Lundström, Temporal studies on the deposition of complement on human colostrum IgA and serum IgG immobilized on methylated 
silicon, J. Biomed. Mater. Res. 35 (1997) 81-92.

38. L. Tang, L. Liu, H.B. Elwing, Complement activation and inflammation triggered by model biomaterial surfaces, J. Biomed. Mater. Res. 41 (1998) 333-341.

39. P. Tengvall, A. Askendal, I. Lundström, Ellipsometric in vitro studies on the activation of complement by human immunoglobulins $\mathrm{M}$ and $\mathrm{G}$ after adsorption to methylated silicon, Colloids Surf. B, 20 (2001) 51-62.

40. J. Wetterö, A. Askendal, T. Bengtsson, P. Tengvall, On the binding of complement to solid artificial surfaces in vitro, Biomaterials 23 (2002)981-991.

41. J. Andersson, K.N. Ekdahl, R. Larsson, U.R. Nilsson, B. Nilsson, C3 adsorbed to a polymer surface can form an initiating alternative pathway convertase, J. Immunol. 168 (2002) 5786-5791.

42. J. Andersson, K.N. Ekdahl, J.D. Lambris, B. Nilsson, Binding of C3 fragments on top of adsorbed plasma proteins during complement activation on a model biomaterial surface, Biomaterials 26 (2005) 1477-1485.

43. A. Sellborn, M. Andersson, J. Hedlund, J. Andersson, M. Berglin, H. Elwing, Immune complement activation on polystyrene and silicon dioxide surfaces: Impact of reversible IgG adsorption, Mol. Immunol. 42 (2005) 569-574.

44. F. Höök, B. Kasemo, T. Nylander, C. Fant, K. Sott, H. Elwing, Variations in coupled 
water, viscoelastic properties, and film thickness of a Mefp-1 protein film during adsorption and cross-linking: A quartz crystal microbalance with dissipation monitoring, ellipsometry, and surface plasmon resonance study, Anal. Chem. 73 (2001) 5796-5804.

45. E. Reimhult, C. Larsson, B. Kasemo, F. Höök, Simultaneous SPR and QCM-D monitoring measurements of biomolecular adsorption events involving structural transformations and variations in coupled water, Anal. Chem. 76 (2004) 7211-7220.

46. A. Ulman, Formation and structure of self-assembled monolayers, Chem. Rev. 96 (1996) 1533-1554.

47. E. Ostuni, L. Yan, G.M. Whitesides, The interaction of proteins and cells with selfassembled monolayers of alkanethiolates on gold and silver, Colloids Surf. B 15 (1999) 3-30.

48. J.C. Love, L.A. Estroff, J.K. Kriebel, R.G. Nuzzo, G.M. Whitesides, Self-assembled monolayers of thiolates on metals as a form of nanotechnology, Chem. Rev. 105 (2005) 1103-1169.

49. W. Senaratne, L. Andruzzi, C.K. Ober, Self-assembled monolayers and polymer brushes in biotechnology: Current applications and future perspectives, Biomacromolecules 6 (2005) 2427-2448. 
50. R.G. Nuzzo, B.R. Zegarski, L.H. Dubois, Fundamental studies of the chemisorption of organosulfur compounds on $\mathrm{Au}(111)$. Implications for molecular self-assembly on gold surfaces, J. Am. Chem. Soc. 109 (1987) 733-740.

51. R.G. Nuzzo, L.H. Dubois, D.L. Allara, Fundamental studies of microscopic wetting on organic surfaces. 1. Formation and structural characterization of a self-consistent series of polyfunctional organic monolayers, J. Am. Chem. Soc. 112 (1990) 558-569.

52. M.D. Porter, T.B. Bright, D.L. Allara, C.E.D. Chidsey, Spontaneously organized molecular assemblies. 4. Structural characterization of n-alkyl thiol monolayers on gold by optical ellipsometry, infrared spectroscopy, and electrochemistry, J. Am. Chem. Soc. 109 (1987) 3559-3568.

53. L. Strong, G.M. Whitesides, Structures of self-assembled monolayer films of organosulfur compounds adsorbed on gold single crystals: Electron diffraction studies, Langmuir 4 (1988) 546-558.

54. I. Hirata, Y. Hioki, M. Toda, T. Kitazawa, Y. Murakami, E. Kitano, H. Kitamura, Y. Ikada, H. Iwata, Deposition of complement protein C3b on mixed self-assembled monolayers carrying surface hydroxyl and methyl groups studied by surface plasmon resonance, J. Biomed. Mater. Res. 66A (2003) 669-676.

55. C.D. Bain, J. Evall, G.M. Whitesides, Formation of monolayers by the coadsorption 
of thiols on gold: Variation in the head group, tail group, and solvent, J. Am. Chem. Soc. $111(1989)$ 7155-7164.

56. Y. Arima, H. Iwata, Effect of wettability and surface functional groups on protein adsorption and cell adhesion using well-defined mixed self-assembled monolayers, Biomaterials 28 (2007) 3074-3082.

57. R.A. Frazier, G. Matthijs, M.C. Davies, C.J. Roberts, E. Schacht, S.J.B. Tendler, Characterization of protein-resistant dextran monolayers, Biomaterials 21 (2000) 957-966.

58. L.D. Unsworth, H. Sheardown, J.L. Brash, Protein resistance of surfaces prepared by sorption of end-thiolated poly(ethylene glycol) to gold: Effect of surface chain density, Langmuir 21 (2005) 1036-1041.

59. F. Zhang, E.T. Kang, K.G. Neoh, W. Huang, Modification of gold surface by grafting of poly(ethylene glycol) for reduction in protein adsorption and platelet adhesion, J. Biomater. Sci. Polymer Ed. 12 (2001) 515-531.

60. Y. Arima, M. Kawagoe, M. Toda, H. Iwata, Complement activation by polymers carrying hydroxyl groups, ACS Appl. Mater. Interfaces 1 (2009) 2400-2407.

61. Y. Arima, M. Kawagoe, M. Furuta, M. Toda, H. Iwata, Effect of swelling of poly(vinyl alcohol) layers on complement activation, Biomaterials 31 (2010) 6926- 
6933.

62. M.R. Nejadnik, A.L.J. Olsson, P.K. Sharma, H.C. van der Mei, W. Norde, H.J. Busscher, Adsorption of pluronic F-127 on surfaces with different hydrophobicities probed by quartz crystal microbalance with dissipation, Langmuir 25 (2009) 62456249.

63. B. Liedberg, I. Lundström, E. Stenberg, Principles of biosensing with an extended coupling matrix and surface plasmon resonance, Sens. Actuators B 11 (1993) 63-72.

64. I. Hirata, M. Okazaki, H. Iwata, Simple method for preparation of ultra-thin poly(Nisopropylacrylamide) hydrogel layers and characterization of their thermoresponsive properties, Polymer 45 (2004) 5569-5578.

65. R.P. Richter, R. Bérat, A.R. Brisson, Formation of solid-supported lipid bilayer: An integrated view, Langmuir 22 (2006) 3497-3505.

66. M. Tanaka, E. Sachmann, Polymer-supported membranes as models of the cell surface, Nature 437 (2005) 656-663.

67. I. Hirata, Y. Morimoto, Y. Murakami, H. Iwata, E. Kitano, H. Kitamura, Y. Ikada, Study of complement activation on well-defined surfaces using surface plasmon resonance, Colloids Surf. B 18 (2000) 285-292.

68. M. Toda, T. Kitazawa, I. Hirata, Y. Hirano, H. Iwata, Complement activation on 
surfaces carrying amino groups, Biomaterials 29 (2008) 407-417.

69. M. Toda, Y. Arima, H. Iwata, Complement activation on degraded polyethylene glycol-covered surface, Acta Biomaterialia 6 (2010) 2642-2649.

70. M. Toda, H. Iwata, Effects of hydrophobicity and electrostatic charge on complement activation by amino groups, ACS Appl. Mater. Interfaces 2 (2010) 1107-1113.

71. A. Sahu, D. Morikis, J.D. Lambris, Compstatin, a peptide inhibitor of complement, exhibits species-specific binding to complement component C3, Mol. Immunol. 39 (2003) 557-566.

72. B. Nilsson, R. Larsson, J. Hong, G. Elgue, K.N. Ekdahl, A. Sahu, J.D. Lambris, Compstatin inhibits complement and cellular activation in whole blood in two models of extracorporeal circulation, Blood 92 (1998) 1661-1667.

73. A. Sahu, B.K. Kay, J.D. Lambris, Inhibition of human complement by a C3-binding peptide isolated from a phage-displayed random peptide library, $\mathrm{J}$. Immunol. 157 (1996) 884-891.

74. U.R. Nilsson, Deposition of $\mathrm{C} 3 \mathrm{~b} / \mathrm{iC} 3 \mathrm{~b}$ leads to the concealment of antigens, immunoglobulins and bound $\mathrm{Clq}$ in complement-activating immune complexes, Mol. Immunol. 38 (2001) 151-160. 
75. T. Ishida, M. Ichihara, X. Wang, K. Yamamoto, J. Kimura, E. Majima, H. Kiwada, Injection of PEGylated liposomes in rats elicits PEG-specific IgM, which is responsible for rapid elimination of a second dose of PEGylated liposomes, J. Control. Release 112 (2006) 15-25.

76. M.K. Pangburn, H.J. Muller-Eberhard, Relation of putative thioester bond in C3 to activation of the alternative pathway and the binding of $\mathrm{C} 3 \mathrm{~b}$ to biological targets of complement, J. Exp. Med. 152 (1980) 1102-1114.

77. S.K.A. Law, The covalent binding reaction of C3 and C4, Ann. NY Acad. Sci. 421 (1983) 246-258.

78. R.B. Sim, E. Sim, Autolytic fragmentation of complement components C3 and C4 and its relationship to covalent binding activity, Ann. NY Acad. Sci. 421 (1983) 259276.

79. M.L. Nucci, D. Shorr, A. Abuchowski, The therapeutic values of poly(ethylene glycol)-modified proteins, Adv. Drug Deliv. Rev. 6 (1991) 133-151.

80. J.M. Harris, R.B. Chess, Effect of PEGylation on pharmaceuticals, Nat. Rev. Drug Discov. 2 (2003) 214-221.

81. R. Duncan, The dawning era of polymer therapeutics, Nat. Rev. Drug Discov. 2 (2003) 347-360. 
82. B. Uziely, S. Jeffers, R. Isacson, K. Kutsch, D. Wei-Tsao, Z. Yehoshua, E. Libson, F.M. Muggia, A. Gabizon Liposomal doxorubicin: antitumor activity and unique toxicities during two complementary phase I studies, J. Clin. Oncol. 13 (1995) $1777-1785$.

83. S. de Marie, Liposomal and lipid-based formulations of amphotericin B, Leukemia 10 (1996) S93-S96.

84. D.S. Alberts, D.J. Garcia, Safety aspects of pegylated liposomal doxorubicin in patients with cancer, Drugs S4 (1997) 30-45.

85. K.M. Skubitz, A.P. Skubitz, Mechanism of transient dyspnea induced by pegylatedliposomal doxorubicin (Doxil), Anticancer Drugs 9 (1998) 45-50.

86. P. Laverman, A.H. Brouwers, E.T.M. Dams, W.J.G. Oyen, G. Storm, N. Van Rooijen, F.H.M. Corstens, O.C. Boerman, Preclinical and clinical evidence for disappearance of long-circulating characteristics of polyethylene glycol liposomes at low lipid dose, J. Pharmacol. Exp. Ther. 293 (2000) 996-1001.

87. S.M. Moghimi, J. Szebeni, Stealth liposomes and long circulating nanoparticles: critical issues in pharmacokinetics, opsonization and protein-binding properties, Prog. Lipid Res. 42 (2003) 463-478.

88. S.M. Moghimi, A.J. Andersen, S.H. Hashemi, B. Lettiero, D. Ahmadvand, A.C. 
Hunter, T.L. Andresen, I. Hamad, J. Szebeni, Complement activation cascade triggered by PEG-PL engineered nanomedicines and carbon nanotubes: The challenges ahead, J. Control. Release 146 (2010) 175-181.

89. A. Vonarbourg, C. Passirani, P. Saulnier, J.P. Benoit, Parameters influencing the stealthiness of colloidal drug delivery system, Biomaterials 27 (2006) 4356-4373.

90. Y. Arima, M. Toda, H. Iwata, Complement activation on surfaces modified with ethylene glycol units, Biomaterials 29 (2008) 551-560.

91. C. Pale-Grosdemange, E.S. Simon, K.L. Prime, G.M. Whitesides, Formation of selfassembled monolayers by chemisorption of derivatives of oligo(ethylene glycol) of structure $\left.\mathrm{HS}\left(\mathrm{CH}_{2}\right)_{11} \mathrm{OCH}_{2} \mathrm{CH}_{2}\right)_{\mathrm{m}} \mathrm{OH}$ on gold, J. Am. Chem. Soc. 113 (1991) 12-20.

92. K.L. Prime, G.M. Whitesides, Adsorption of proteins onto surfaces containing endattached oligo(ethylene oxide): A model system using self-assembled monolayers, J. Am. Chem. Soc. 115 (1993) 10714-10721.

93. D.E. Owens III, N.A. Peppas, Opsonization, biodistribution, and pharmacokinetics of polymeric nanoparticles, Int. J. Pharm. 307 (2006) 93-102.

94. O.A. Mkhatresh, F. Heatley, A ${ }^{13} \mathrm{C}$ NMR study of the products and mechanism of the thermal oxidative degradation of poly(ethylene oxide), Macromol. Chem. Phys. 203 (2002) 2273-2280. 
95. V. Videm, T.E. Mollens, Human complement activation by polygeline and dextran 70, Scand. J. Immunol. 39 (1994) 314-320.

96. M.P. Carreno, D. Labarre, M. Jozefowicz, M.D. Kazatchkine, The ability of Sephadex to activate human-complement is suppressed in specifically substituted functional sephadex derivatives. Mol. Immunol. 5 (1988) 165-171.

97. C. Passirani, G. Barratt, J.P. Devissaguet, D. Labarre, Interactions of nanoparticles bearing heparin or dextran covalently bound to poly(methyl methacrylate) with the complement system, Life Sci. 62 (1998) 775-785.

98. M.T. Peracchia, C. Vauthier, C. Passirani, P. Couvreur, D. Labarre, Complement concumption by poly(ethylene glycol) in different conformations chemically coupled to poly(isobutyl 2-cyanoacrylate) nanoparticles, Life Sci. 61 (1997) 749761.

99. I. Hamad, O. Al-Hanbali, A.C. Hunter, K.J. Rutt, T.L. Andresen, S.M. Moghimi, Distinct polymer architecture mediates switching of complement activation pathways at the nanosphere-serum interface: Implications for stealth nanoparticle engineering, ACS Nano 4 (2010) 6629-6638.

100. P. Gros, F.J. Milder, B.J.C. Janssen, Complement driven by conformational changes, Nat. Rev. Immunol. 8 (2008) 48-58. 
101. B.J.C. Janssen, A. Christodoulidou, A. McCarthy, J.D. Lambris, P. Gros, Structure of $\mathrm{C} 3 \mathrm{~b}$ reveals conformational changes that underlie complement activity, Nature 444 (2006) 213-216.

102. S.H.M. Rooijakkers, J. Wu, M. Ruyken, R. van Domselaar, K.L. Plankern, A. Tzekou, D. Ricklin, J.D. Lambris, B.J.C. Janssen, J.A.G. van Strijp, P. Gros, Structural and functional implications of the alternative complement pathway $\mathrm{C} 3$ convertase stabilized by a staphylococcal inhibitor, Nat. Immunol. 10 (2009) 721727.

103. E. Torreira, A. Tortajada, T. Montes, S.R. de Córdoba, O. Llorca, 3D structure of the $\mathrm{C} 3 \mathrm{bB}$ complex provides insights into the activation and regulation of the complement alternative pathway convertase, Proc. Natl. Acad. Sci. USA 106 (2009) $882-887$.

104. J. Wu, Y.Q. Wu, D. Ricklin, B.J.C. Janssen, J.D. Lambris, P. Gros, Structure of complement fragment $\mathrm{C} 3 \mathrm{~b}$-factor $\mathrm{H}$ and implications for host protection by complement regulators, Nat. Immunol. 10 (2009) 728-733.

105. F. Forneris, D. Ricklin, J. Wu, A. Tzekou, R.S. Wallace, J.D. Lambris, P. Gros, Structures of $\mathrm{C} 3 \mathrm{~b}$ in complex with factors $\mathrm{B}$ and $\mathrm{D}$ give insight into complement convertase formation, Science 330 (2010) 1816-1820. 
106. H.P. Morgan, C.Q. Schmidt, M. Guariento, B.S. Blaum, D. Gillespie, A.P.

Herbert, D. Kavanagh, H.D.T. Mertens, D.I. Svergun, C.M. Johansson, D. Uhrín, P.N. Barlow, J.P. Hannan, Structural basis for engagement by complement factor $\mathrm{H}$ of C3b on a self surface, Nat. Struc. Mol. Biol. 18 (2011) 463-470.

107. T. Kajander, M.J. Lehtinen, S. Hyvärinen, A. Bhattacharjee, E. Leung, D.E. Isenman, S. Meri, A. Goldman, T.S. Jokiranta, Dual interaction of factor H with C3d and glycosaminoglycans in host-nonhost discrimination by complement, Proc. Natl. Acad. Sci. USA 108 (2011) 2897-2902.

108. U. Alon, An introduction to systems biology: Design principles of biological circuits, Chapman and Hall/CRC, Boca Raton, 2007. 


\section{Figure captions}

Figure 1. (a) Schematic illustration of the Kretschmann configuration for SPR. Surface plasmon is excited at metal/ambient interface when the evanescent component of wave vector of incoming light $\left(k_{\mathrm{ev}}\right)$ is equal to the wave vector of the propagating surface plasmon $\left(k_{\mathrm{sp}}\right)$. (b) Reflectance as a function of incident angle before (black) and after (red) adsorption of substances. (c) Schematic representation of a SPR apparatus.

Figure 2. Schematic illustration of an SPR profile during a protein adsorption experiment. (a) Sequential step in protein adsorption onto a material surface; surface exposed to buffer (I), upon exposure to protein solution (II), adsorbed with protein (III), and rinsed with buffer (IV). (b) Reflectance as a function of incident angle before (black) and after (red) adsorption of proteins. A shift in the SPR angle $\left(\Delta \theta_{\mathrm{SPR}}\right)$ occurs in a manner dependent on the amount of adsorbed proteins. (c) In real-time monitoring, reflectance at a specific incident angle (dashed line in (b)) is plotted as a function of time. Points I to IV correspond to steps in (a). Change in reflectance after protein adsorption $(\Delta R)$ is finally converted to $\Delta \theta_{\mathrm{SPR}}$ to calculate the amount of adsorbed proteins. 
Figure 3. Model surfaces used for complement monitoring by SPR.

Figure 4. Composition (a) and water contact angles (b) of SAMs formed from various reaction mixtures of 11-mercapto-1-undecanol and several methyl-terminated alkanethiols with different alkyl chain length. The composition of SAMs was determined by FTIR-RAS spectra. Modified from Ref. [54].

Figure 5. Time curve of normal human serum proteins adsorption on OH-SAM and subsequent binding of anti-C3b antiserum. Modified from Ref. [67].

Figure 6. Model of complement activation on a biomaterial surface. Nonspecifically adsorbed immunoglobulins (a) initiate the classical pathway while conformationally changed C3 upon nonspecific adsorption (b), C3b covalently bound to nonspecifically adsorbed serum proteins (c), and C3b covalently bound to hydroxyl or amino groups of biomaterial (d) initiate the alternative pathway.

Figure 7 . The amounts of adsorbed serum proteins from $10 \%$ human serum and the subsequent binding of antibodies to SAMs carrying different terminal groups. Asterisks 
indicate that adsorption of serum proteins or binding of anti-C3b antibody was not detected by SPR. Summarized from Ref. [68,70].

Figure 8 . The amounts of adsorbed serum proteins from $10 \%$ human serum (open symbols) and adsorbed human serum albumin (HSA) (closed symbols) from a single HSA solution as a function of hydroxyl density of mixed SAMs carrying hydroxyl and methyl groups. Mixed SAMs were formed from various reaction mixtures of 11mercapto-1-undecanol and several methyl-terminated alkanethiols with different alkyl chain length (see Fig. 4). Modified from Ref. [54].

Figure 9. SPR sensorgrams during exposure of HS-TEGOH and HS-mPEG surfaces to 10\% human serum (a) and anti-C3b antiserum (b). Figures also include SPR sensorgrams when HS-TEGOH surface was exposed to $10 \%$ human serum in the presence of $10 \mathrm{mM}$ EDTA to block the complement activation [90].

Figure 10. Amounts of serum proteins adsorbed on PVA surfaces and subsequent binding of anti-C3b antibodies to serum protein layers formed on those surfaces. Data shown are means $\pm \mathrm{SD}(n=3)$. PVA percent: PVA concentration for spin-coating. Types 
of serum samples: serum, human serum; serum + EDTA, human serum $+10 \mathrm{mM}$

EDTA; serum + EGTA, human serum + $10 \mathrm{mM} \mathrm{EGTA} \mathrm{+} 2.5 \mathrm{mM} \mathrm{MgCl}_{2}$. Asterisks

indicate that adsorption of serum proteins or binding of anti-C3b antibody was not detected by SPR [61]. 
(a)

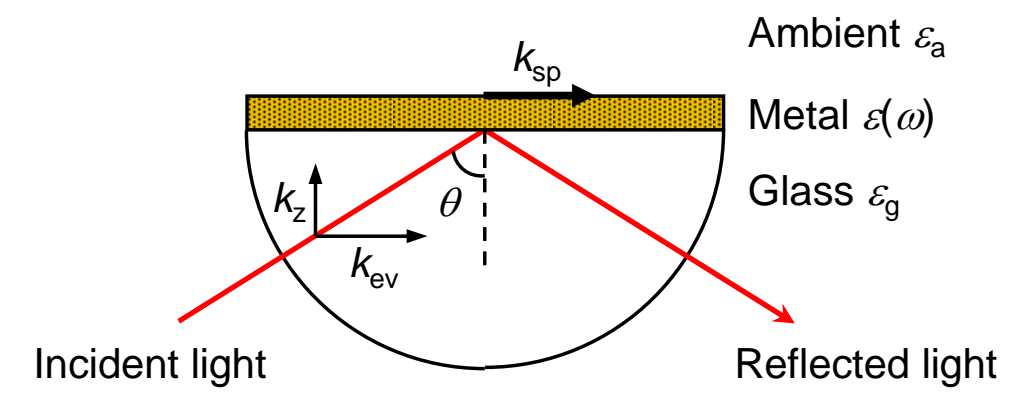

(c)

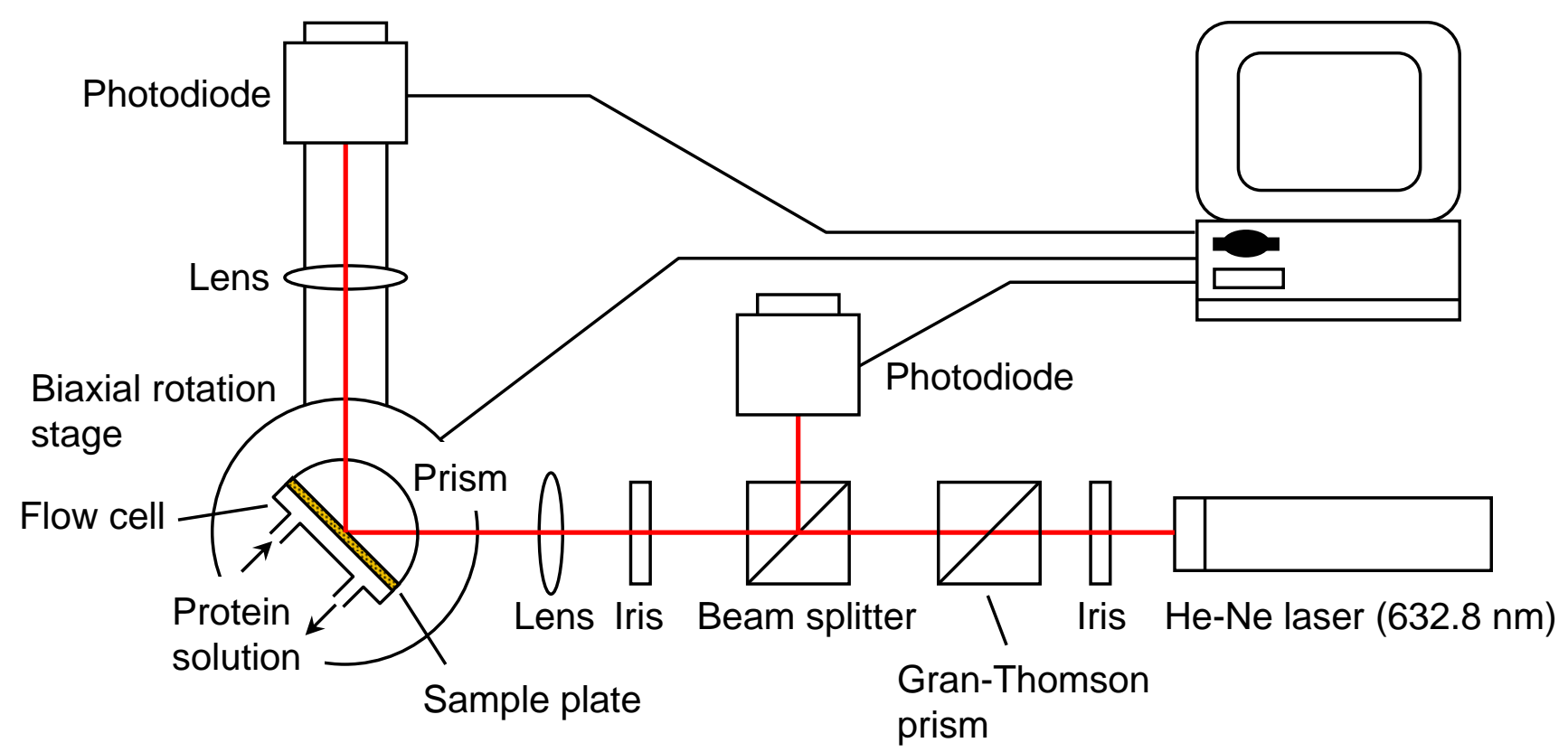

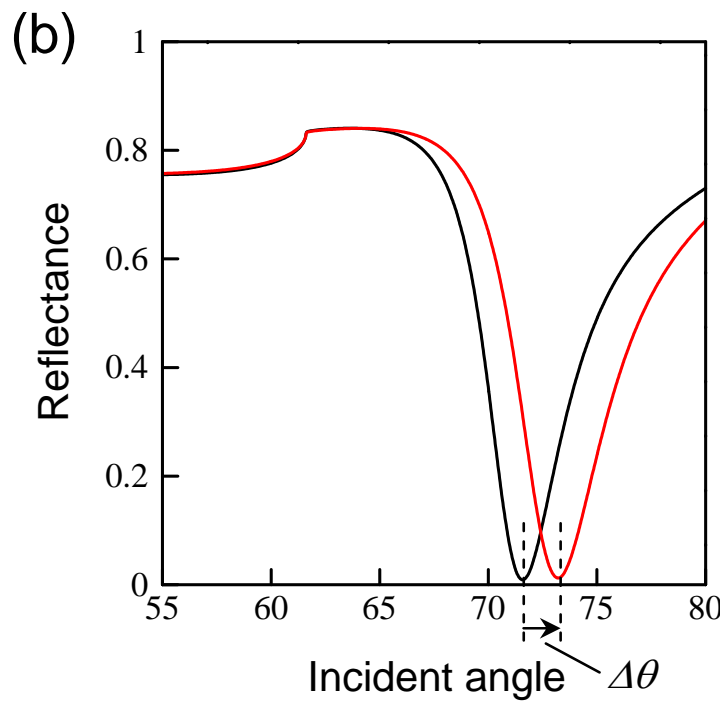

Figure 1 
(a)

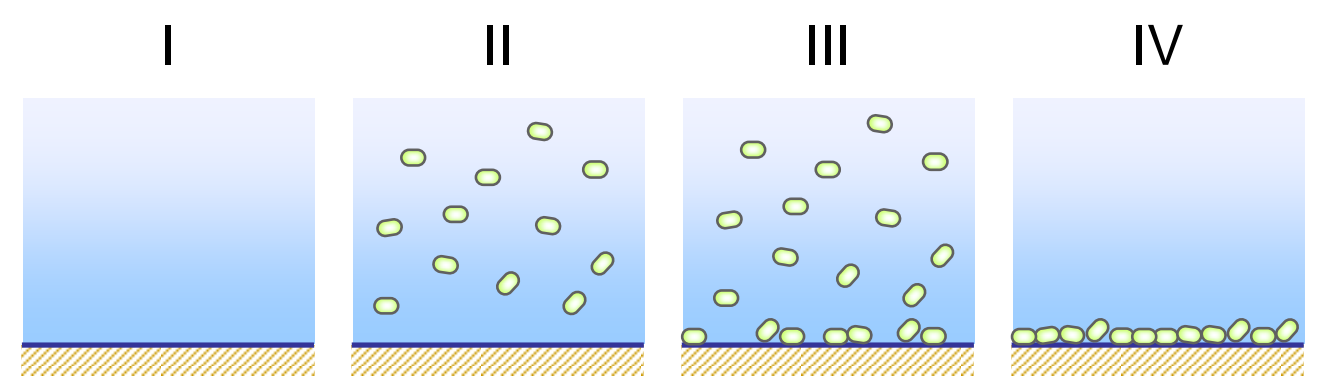

(b)

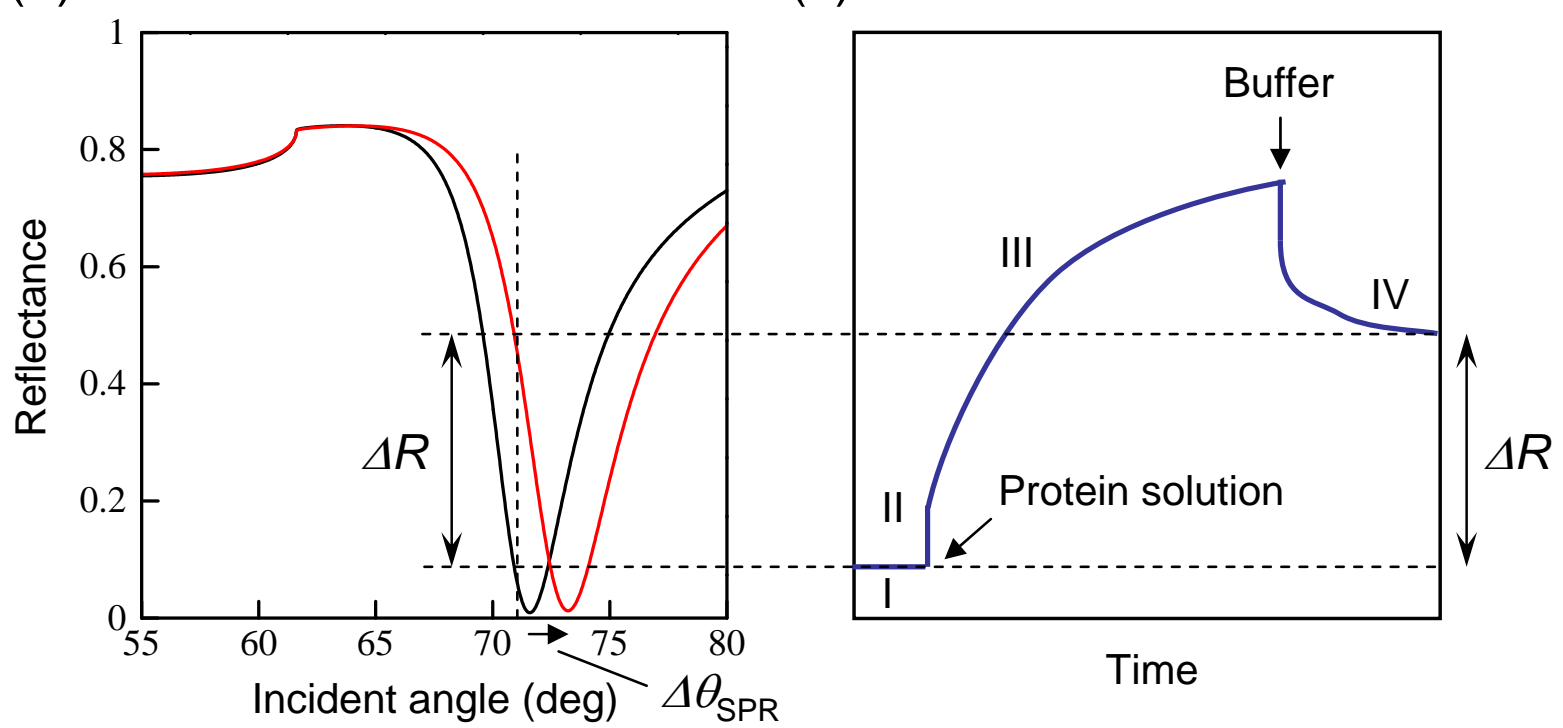

Figure 2 
Self-assembled monolayers

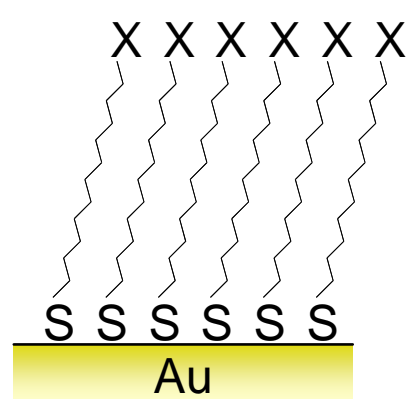

X: $-\mathrm{CH}_{3}$ (hydrophobic)

$-\mathrm{OH},-\left(\mathrm{OCH}_{2} \mathrm{CH}_{2}\right)_{n} \mathrm{OH}$ (nonionic) - $\mathrm{COOH}$ (anionic)

$-\mathrm{NH}_{2}$ (cationic)

Polymer coatings

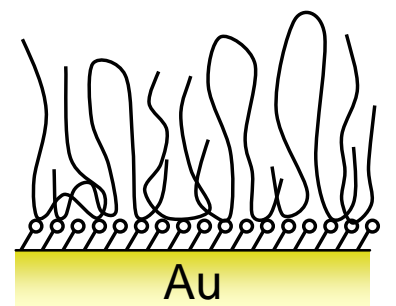

Lipid membranes

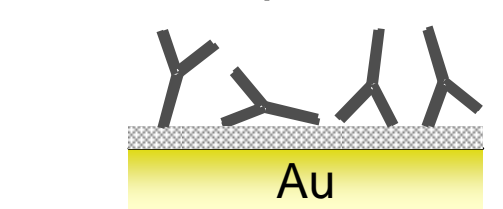

Figure 3 


$$
=\begin{aligned}
& \mathrm{S}\left(\mathrm{CH}_{2}\right)_{11} \mathrm{OH} \\
& \mathrm{S}\left(\mathrm{CH}_{2}\right)_{\mathrm{n}} \mathrm{CH}_{3}
\end{aligned} \quad(\mathrm{n}: 8,11,15)
$$

(a)

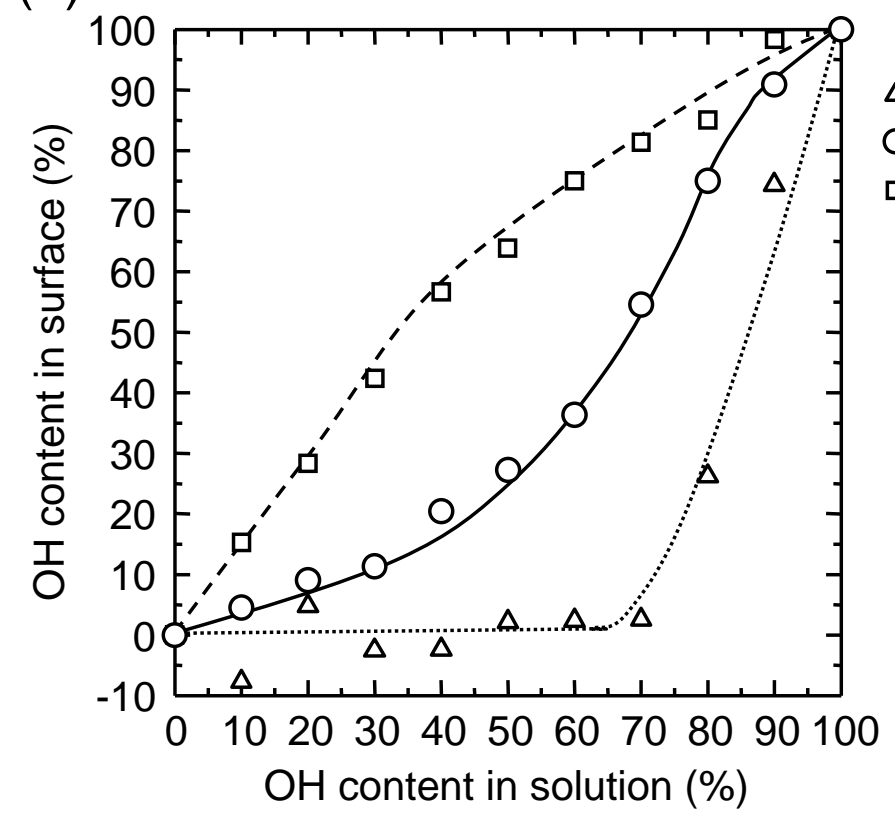

(b)

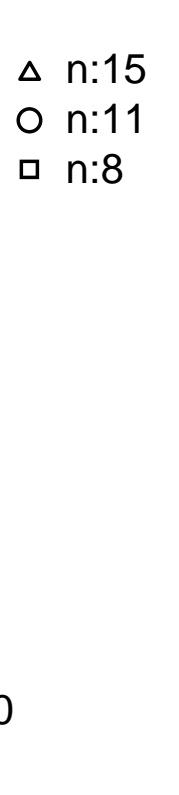

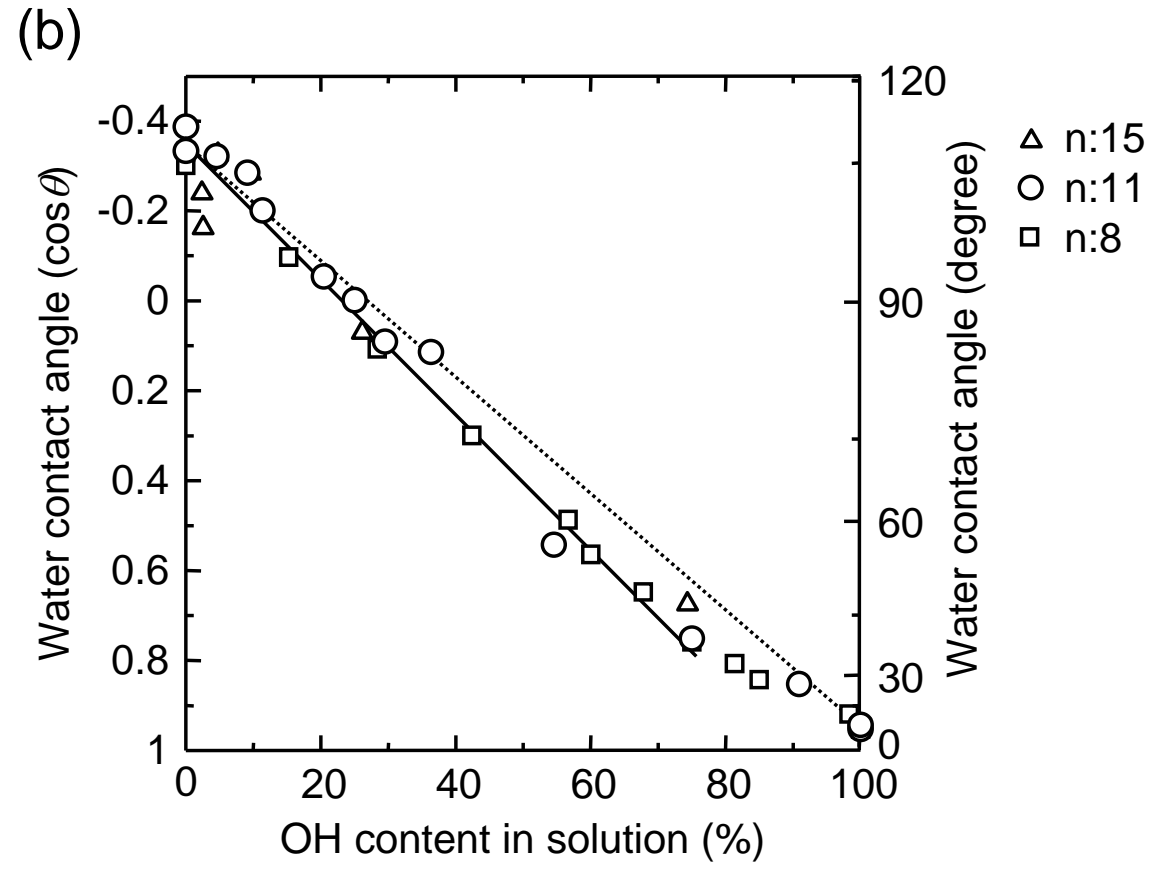

Figure 4 


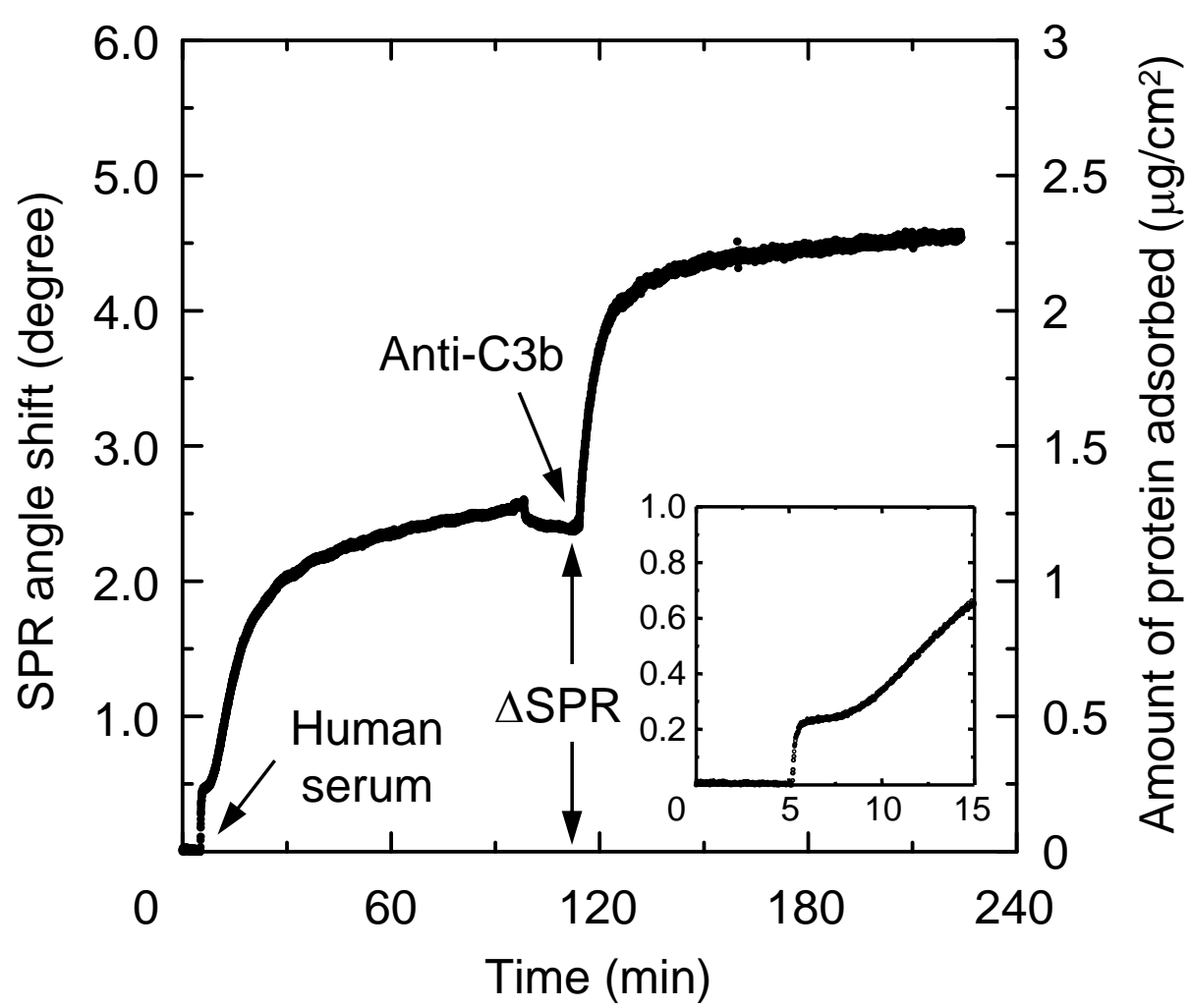

Figure 5 


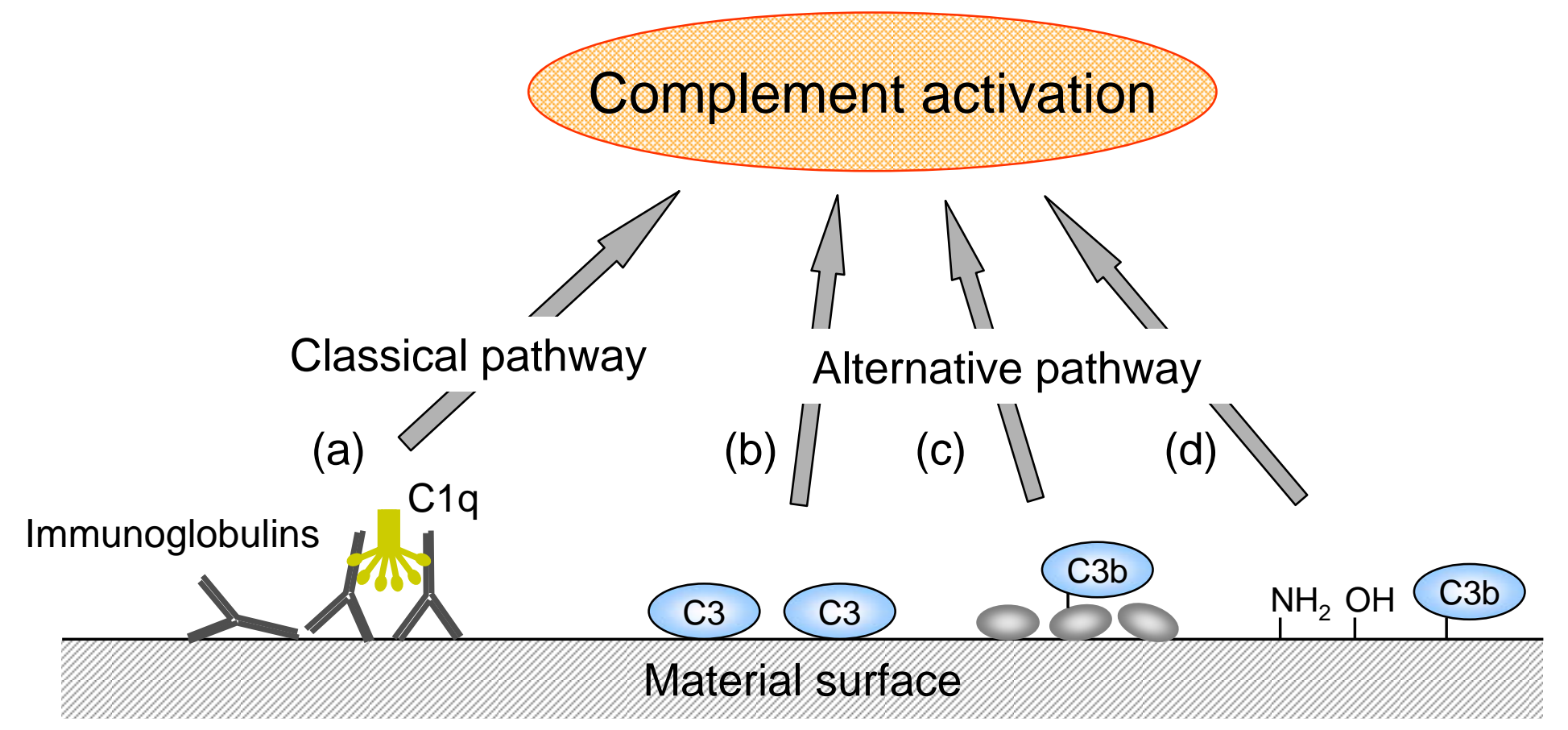

Figure 6 


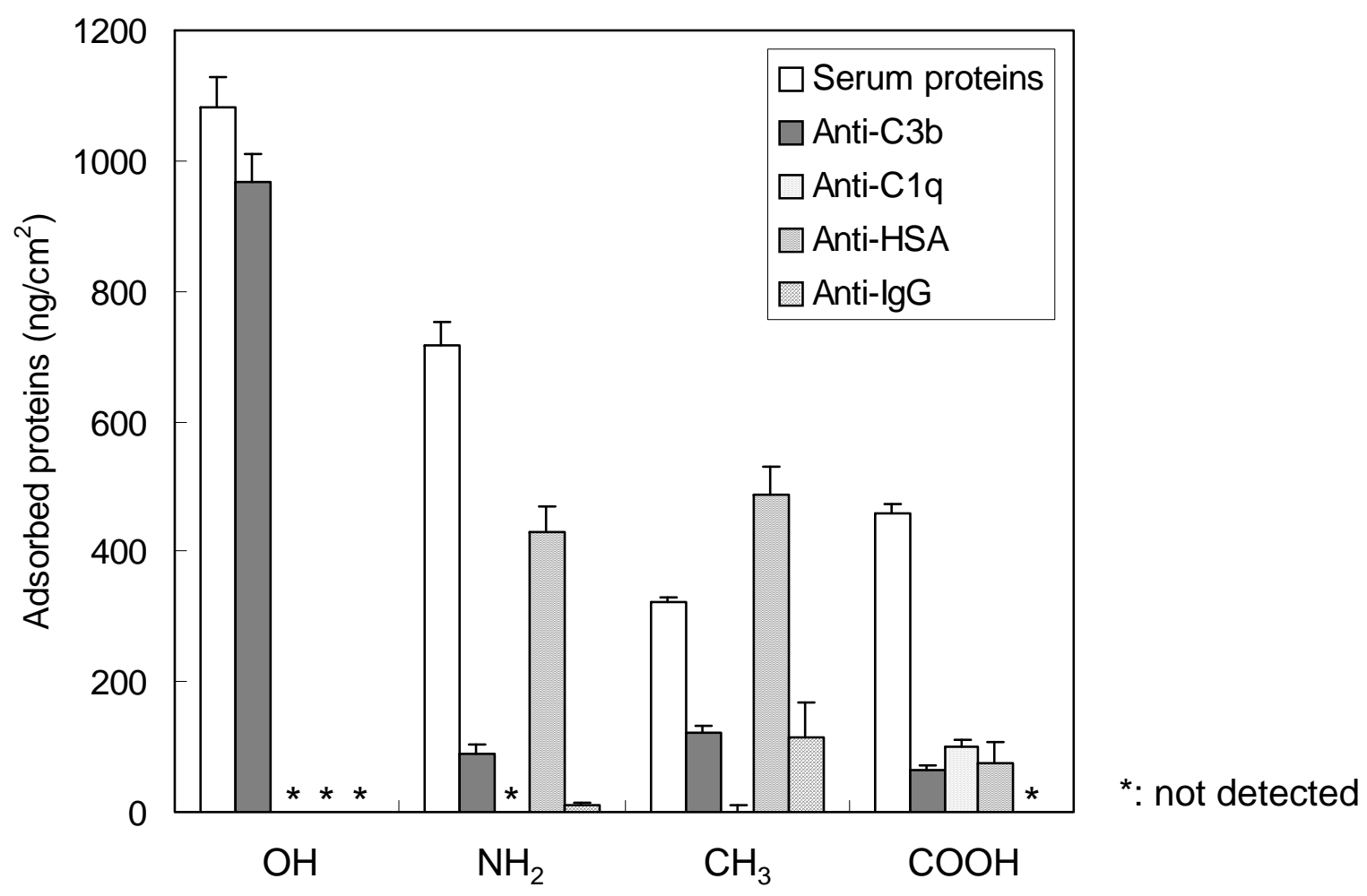

Figure 7 


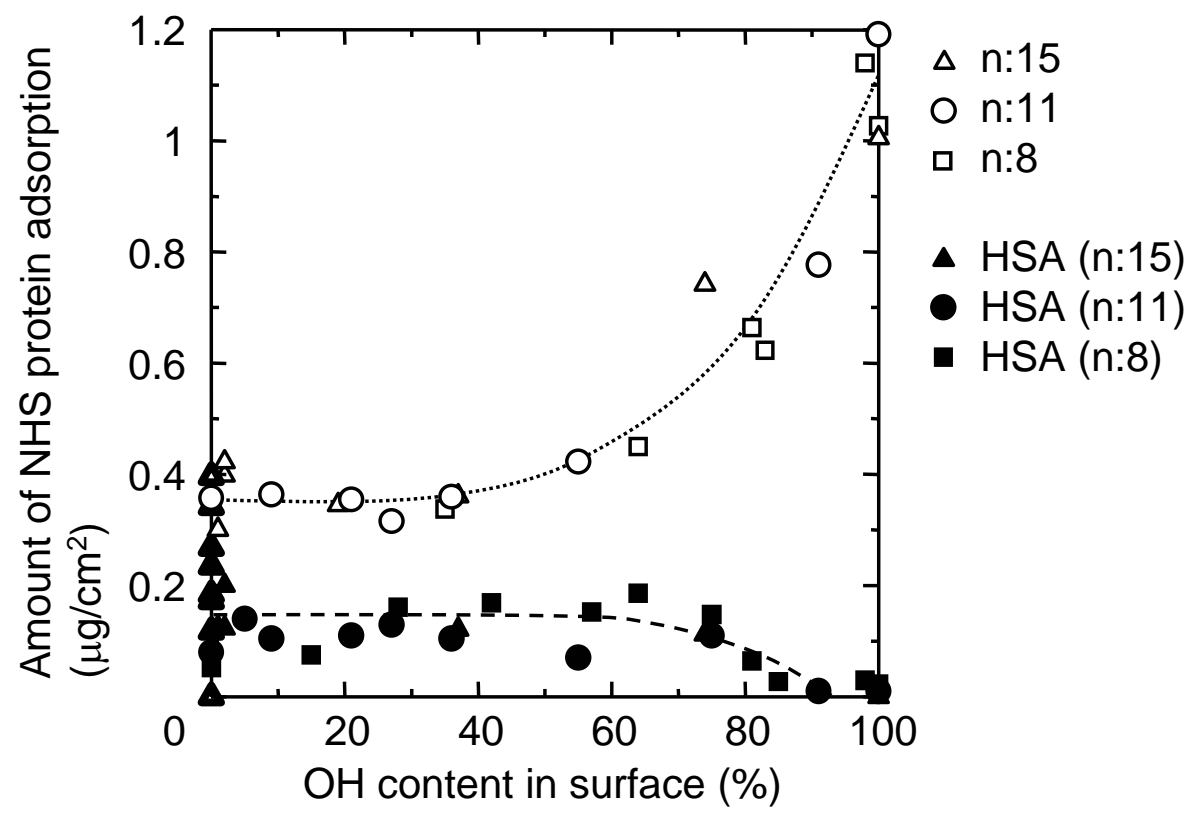

Figure 8 
HS-mPEG

$\mathrm{HS}-\mathrm{CH}_{2} \mathrm{CH}_{2}\left(\mathrm{OCH}_{2} \mathrm{CH}_{2}\right)_{\mathrm{n}}-\mathrm{OCH}_{3}$
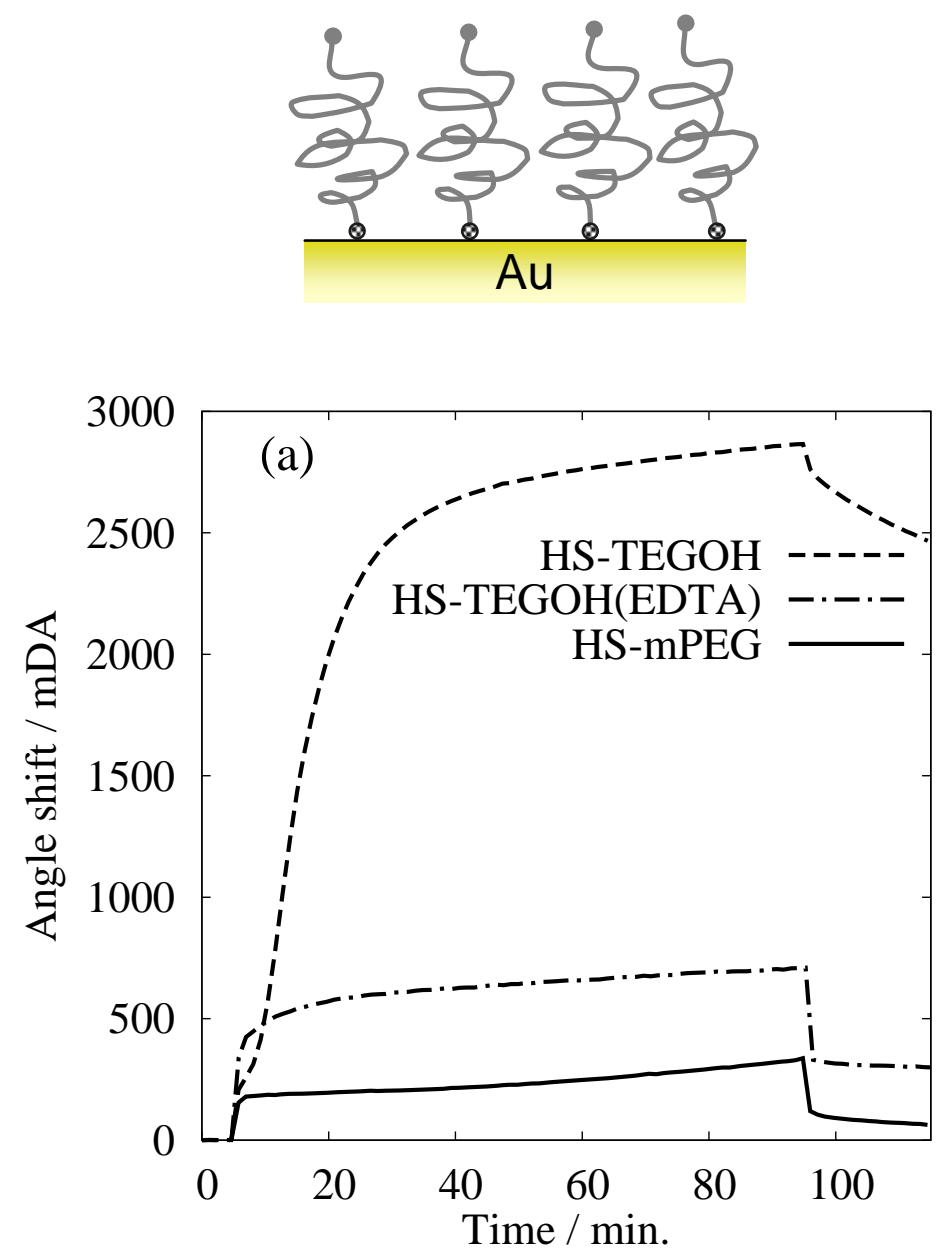

\section{HS-TEGOH}

$\mathrm{HS}-\left(\mathrm{CH}_{2}\right)_{11}-\left(\mathrm{OCH}_{2} \mathrm{CH}_{2}\right)_{3}-\mathrm{OH}$
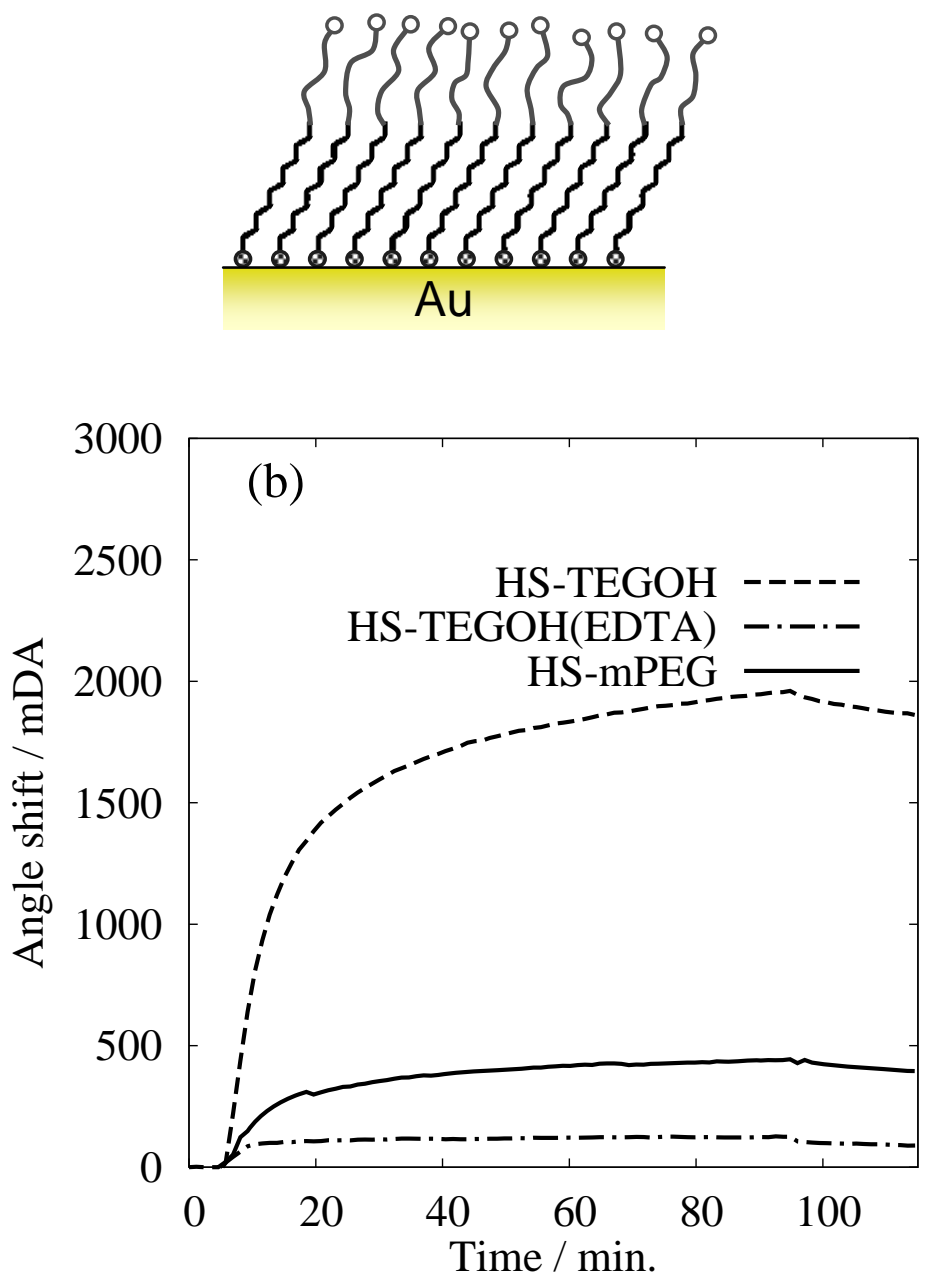

Figure 9 


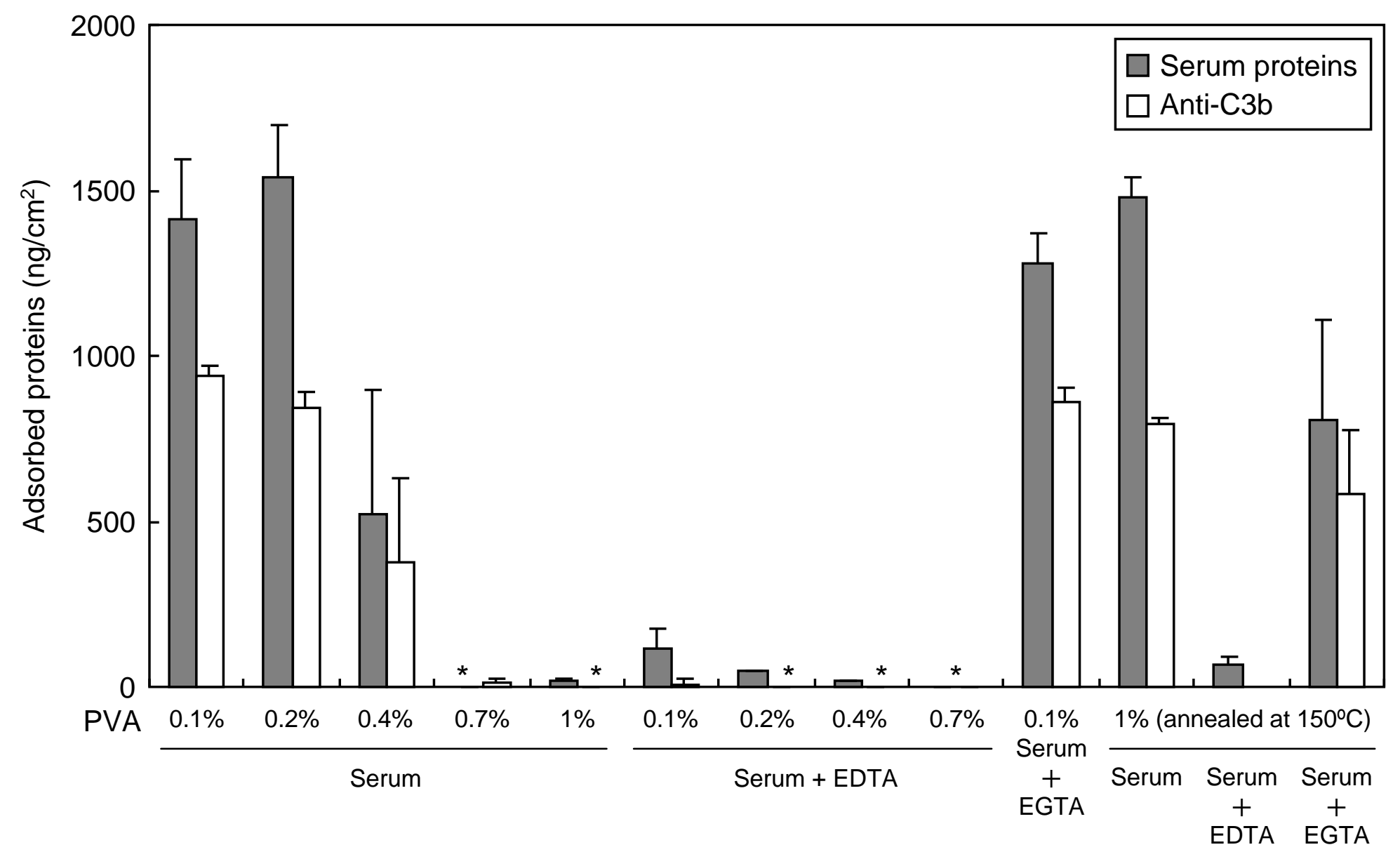

Figure 10 
Table 1. Methods used for complement research

\begin{tabular}{|c|c|c|c|c|c|}
\hline & $\begin{array}{l}\text { Requirement of } \\
\text { materials }\end{array}$ & Information & Monitoring & Labeling & $\begin{array}{l}\text { Detectable complement } \\
\text { proteins }\end{array}$ \\
\hline SPR & $\begin{array}{l}\text { Metal thin layer } \\
\text { on glass (gold, } \\
\text { silver) }\end{array}$ & Thickness & Real-time & No & $\begin{array}{l}\text { Adsorbed protein } \\
\text { (e.g., Immunoglobulins, } \\
\text { C1q, C4, C3b, C3c) }\end{array}$ \\
\hline Ellipsometry & $\begin{array}{l}\text { Refractive } \\
\text { materials } \\
\text { (silicon, gold) }\end{array}$ & Thickness & Real-time & No & $\begin{array}{l}\text { Adsorbed protein } \\
\text { (e.g., Immunoglobulins, } \\
\text { C1q, C4, C3b, C3c) }\end{array}$ \\
\hline QCM & Quartz & $\begin{array}{l}\text { Mass, } \\
\text { viscoelasticity }\end{array}$ & Real-time & No & $\begin{array}{l}\text { Adsorbed protein } \\
\text { (e.g., Immunoglobulins, } \\
\mathrm{C} 1 \mathrm{q}, \mathrm{C} 4, \mathrm{C} 3 \mathrm{~b}, \mathrm{C} 3 \mathrm{c} \text { ) }\end{array}$ \\
\hline ELISA & None & Concentration & End point & $\begin{array}{l}\text { Yes } \\
\text { (detection } \\
\text { antibodies) }\end{array}$ & $\begin{array}{l}\text { Released protein } \\
\text { (e.g., } \mathrm{C} 3 \mathrm{a}, \mathrm{Bb}, \mathrm{C} 5 \mathrm{a} \text {, } \\
\text { SC5b-9) }\end{array}$ \\
\hline
\end{tabular}


Table 2. Characterization of PVA spin-coated surfaces. Modified from Ref. [61].

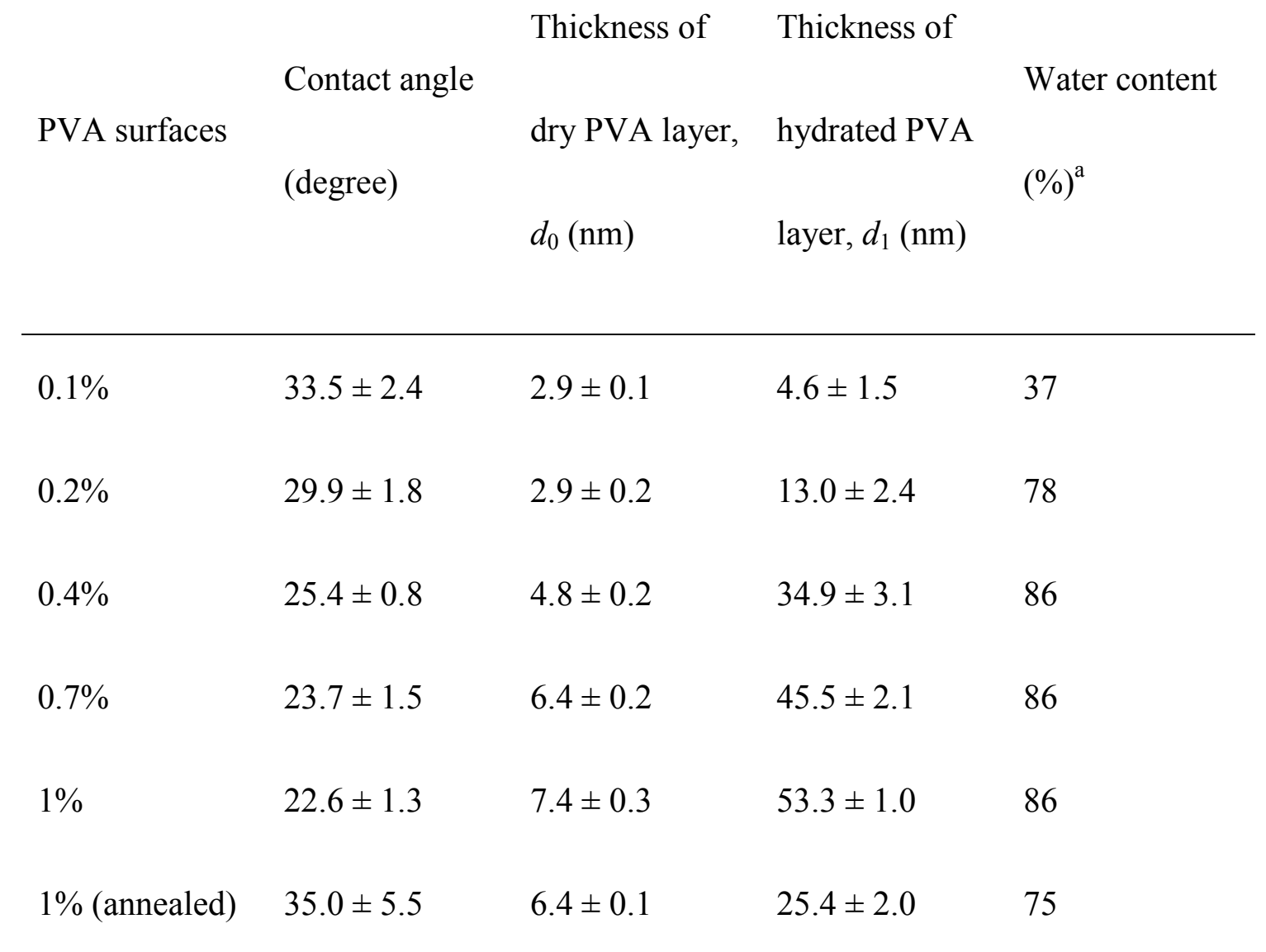

${ }^{\mathrm{a}}:$ determined from $\left(1-\mathrm{d}_{0} / \mathrm{d}_{1}\right) \times 100$ 